\title{
CRANFIELD UNIVERSITY
}

\section{RUOWEI CHEN}

Airport Dominance and Airline Pricing Power:

An Investigation of Hub Premiums in the Chinese Domestic Market

Department of Air Transport, School of Engineering MSc by Research

MSc Thesis

Academic Year: 2012 - 2013

Supervisor: Dr Zheng Lei

December 2013 



\title{
CRANFIELD UNIVERSITY
}

\author{
Department of Air Transport, School of Engineering \\ MSc by Research
}

\author{
MSc Thesis
}

Academic Year 2012 - 2013

\section{RUOWEI CHEN}

Airport Dominance and Airline Pricing Power:

An Investigation of Hub Premiums in the Chinese Domestic Market

\section{Supervisor: Dr Zheng Lei}

December 2013

This thesis is submitted in full fulfilment of the requirements for the degree of Master of Science by Research

(C) Cranfield University 2013. All rights reserved. No part of this publication may be reproduced without the written permission of the copyright owner. 



\section{ABSTRACT}

Concerns on market power conferred by airport dominance and the debates of hub premiums have attracted longstanding attention from governments and academics alike. Most previous studies mainly focus on the fully deregulated markets such as the United States and Europe, what remains unknown is how such effects change when a country evolves from a tightly controlled regime to a deregulated market.

This research analyses the effects of airport dominance on airline pricing power with the empirical study based on the Chinese domestic market using fixedeffect panel data models. Results from the regression analysis indicate that airport dominance is the most important source of pricing power in the gradually deregulated Chinese domestic market. Hub carriers are able to charge higher prices to premium class passengers and non-hub carriers can benefit from the "umbrella effects" of hub premiums. However, hub carriers are not able to translate their airport dominance to pricing power in the economy class market, whereas non-hub carriers even have to reduce the prices as their market shares at major airports increase. This study contributes to the literature by explicitly segmenting the market into economy and premium classes. The results have important policy implications.

Keywords: Airport Dominance, Airfares, Market Power, Hub Premiums, Chinese Domestic Market 



\section{ACKNOWLEDGEMENTS}

First of all, my deepest appreciation goes to my dedicated supervisor $\mathrm{Dr}$ Zheng Lei for his continuous support during my MSc study and writing of this thesis. $\mathrm{He}$ is one of the most passionate, aspiring and devoted researchers I have ever encountered. His enthusiasm has stimulated my interests in academic research which may change the path of my life. I am grateful to his kindness, patience and guidance throughout my study life at Cranfield. I could not have imagined to have a better supervisor and tutor like him for my MSc study.

Besides my supervisor, I would also like to express my sincere gratitude to all the lecturers at Air Transport Department. My special thanks go to the members of my thesis progress review and viva panel: Mr Jim Paton, $\mathrm{Dr}$ Frankie O'Connell and $\mathrm{Dr}$ Gang $\mathrm{Li}$, for their warm encouragement, insightful comments and challenging questions.

My deepest gratitude goes to my beloved family for supporting me spiritually throughout the year. Without their unconditional love, I would have never been here today. I would also like to acknowledge the financial support I have received from my employer COMAC and China Scholarship Council for giving me the opportunity to pursue the postgraduate study in the UK.

Last but not least, to all the fellow students, full-time and part-time, of $2012 / 2013$, thanks for keeping me company on the way of exploring the unknown world. 



\section{TABLE OF CONTENTS}

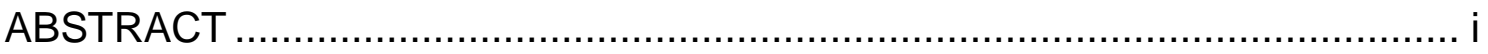

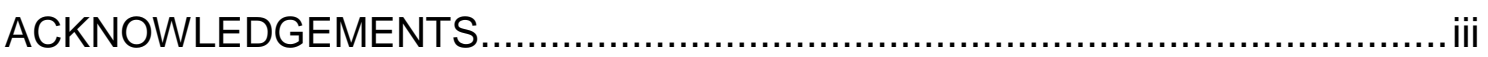

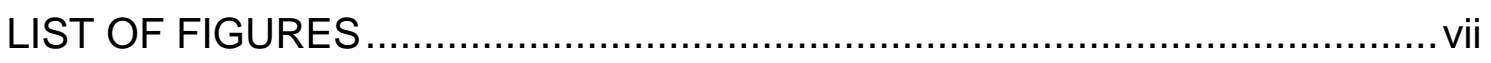

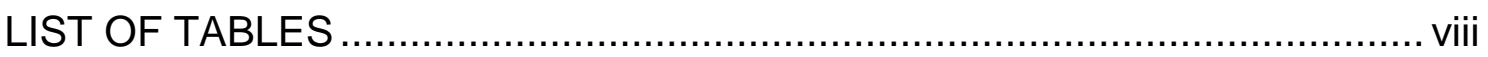

LIST OF ABBREVIATIONS ..............................................................

Chapter 1 Introduction ................................................................................ 1

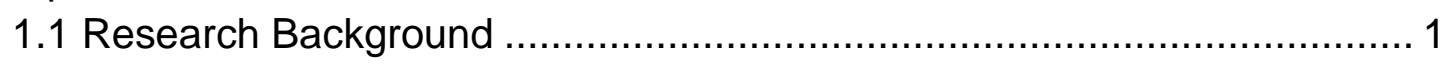

1.2 Aim of the Thesis ......................................................................... 3

1.3 Thesis Structure................................................................................ 4

Chapter 2 Airport Dominance and Airline Pricing Power ............................... 5

2.1 Determinants of Airline Pricing ..................................................... 5

2.2 Airline Market Power and Hub Premiums ............................................. 6

2.2.1 Stage I: Testing the theory of contestable markets ........................ 8

2.2.2 Stage II: Observing the "hub premiums" .................................... 9

2.2.3 Stage III: Disentangling the sources of market power .................... 12

2.3 Empirical Studies for European Market......................................... 16

2.4 Summary ............................................................................ 19

Chapter 3 Deregulation, Airline Consolidation and Hub Airports in China ........ 21

3.1 Deregulation and Airline Consolidation in China .................................. 21

3.2 The Development of Major Hub Airports in China.............................. 22

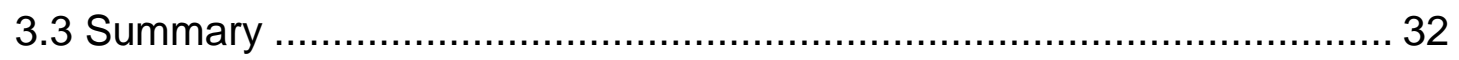

Chapter 4 Methodology .................................................................... 33

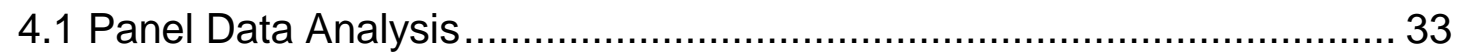

4.1.1 Panel Data Analysis versus Cross Sectional Analysis ................... 33

4.1.2 Estimation Techniques for Panel Data ...................................... 34

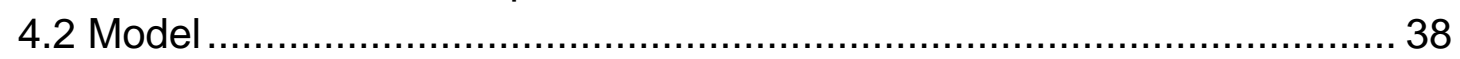

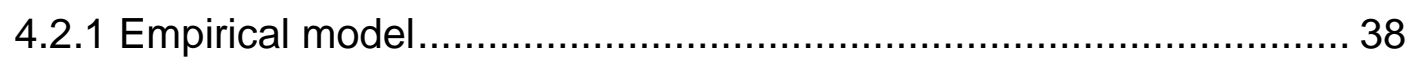

4.2.2 Dependent Variables ....................................................... 39

4.2.3 Market Structure Variables ........................................................ 40

4.2.4 Control Variables..................................................................... 42

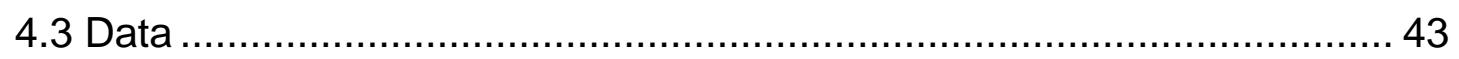

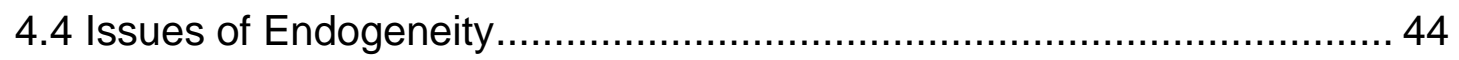

4.4.1 Problem of endogeneity .................................................... 44

4.4.2 Method of instrumental variables (IV) ..................................... 46

4.4.3 Procedures of dealing with endogeneity................................. 46

4.5 Summary .................................................................................. 47

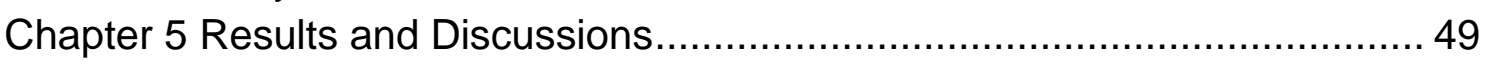

5.1 Summary Statistics .................................................................. 49

5.2 Results of the Regression Models .............................................. 51

5.3 Interpretation of fixed effects time dummies ................................. 55 


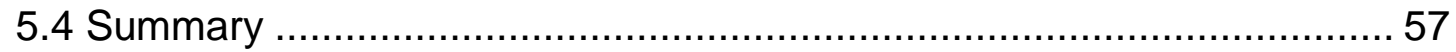

Chapter 6 Summary and Conclusions ...................................................... 59

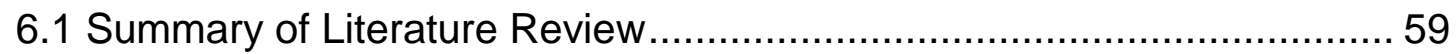

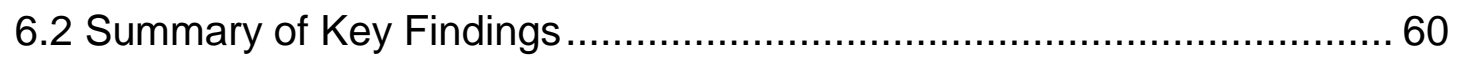

6.3 Originality and Contributions of the Research..................................... 61

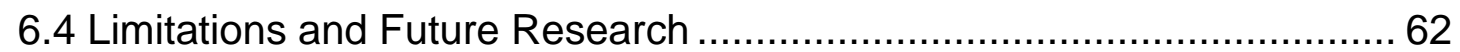

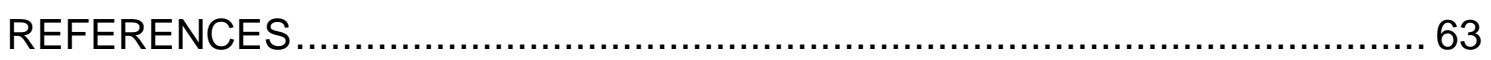

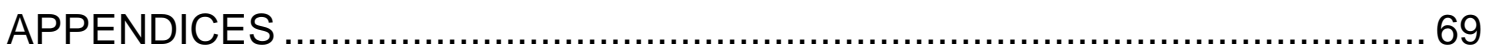




\section{LIST OF FIGURES}

Figure 2-1 Illustrative components of hub premiums ............................... 7

Figure 3-1 Domestic network of Air China (CA) in 2002 (Upper left), 2007 (Upper right) and 2012 (Bottom) .............................................. 23

Figure 3-2 Airport market share of the Big Three at their primary hubs: 2002-

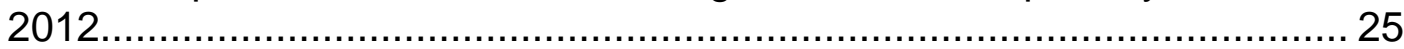

Figure 3-3 HHI of four Major Airports in China: 2002-2012 ........................ 27

Figure 5-1 Fixed effect time dummies ................................................... 56 


\section{LIST OF TABLES}

Table 3-1 Premium passenger percentage comparison between hub carrier and hub airport average level

Table 3-2 Comparisons of Average Fare per Mile (Yield) for Flights from Dominant Airports in $3^{\text {rd }}$ Quarter, 2002.

Table 3-3 Comparisons of Average Fare per Mile (Yield) for Flights from Dominant Airports in $3^{\text {rd }}$ Quarter, 2012 ................................................... 31

Table 5-1 Descriptive Analysis for whole sample ......................................... 49

Table 5-2 Descriptive Analysis for sub-samples............................................ 50

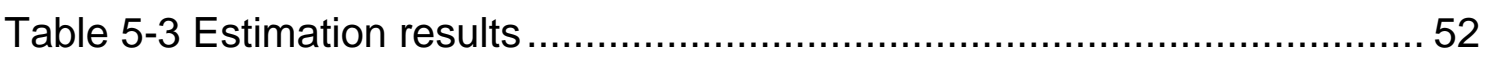

Table B-1 Correlation Matrix for Economy Class Models..........................71

Table B-2 Correlation Matrix for Premium Class Models..........................71 


\section{LIST OF ABBREVIATIONS}

\begin{tabular}{|ll|}
\hline General & \\
\hline ADA & Airline Deregulation Act \\
\hline ADI & Airport Data Intelligence \\
\hline BLUE & Best Linear Unbiased Estimators \\
\hline CAAC & Civil Aviation Administration of China \\
\hline CDPs & Corporate Discount Programs \\
\hline CLRM & Classical Linear Regression Model \\
\hline CPI & Consumer Price Index \\
\hline CRSs & Computer Reservation Systems \\
\hline DB1A & Department of Transportation Data Base 1A \\
\hline DB1B & Department of Transportation Data Base 1B \\
\hline DOT & Department of Transportation \\
\hline DWH & Durbin-Wu Hausman \\
\hline EU & European Union \\
\hline FE & Fixed-effects \\
\hline FSA & Full-service Airline \\
\hline FFPs & Frequent Flyer Programs \\
\hline GAO & General Accounting Office \\
\hline GDP & Gross Domestic Product \\
\hline HHI & Herfindahl-Hirschman Index \\
\hline IV & Instrumental Variable \\
\hline LCC & Low-cost Carrier \\
\hline MIDT & Marketing Information Data Transfer \\
\hline OAG & Official Airline Guide \\
\hline OLS & Ordinary Least Squares \\
\hline OD & Origin and Destination \\
\hline POLS & Pooled Ordinary Least Square \\
\hline RE & Random-effects \\
\hline TACOs & Travel Agent Commission Override Programs \\
\hline UK & The United Kingdoms \\
\hline
\end{tabular}




\begin{tabular}{|ll|}
\hline \multicolumn{2}{|l|}{ IATA Airline Designator } \\
\hline CA & Air China \\
\hline CZ & China Southern Airlines \\
\hline MU & China Eastern Airlines \\
\hline
\end{tabular}

\section{IATA Airport Code}

CAN Guangzhou Baiyun International Airport

CTU Chengdu Shuangliu International Airport

PEK Beijing Capital International Airport

PVG Shanghai Pudong International Airport

SHA Shanghai Hongqiao International Airport 


\section{Chapter 1 Introduction}

\subsection{Research Background}

Historically, airlines were tightly regulated throughout the world based on the Chicago Convention 1944 and series of bilateral air service agreements. Air carriers could not compete on the basis of price since the fares charged by them were regulated by authorities and governments around the world (Narodick, 1972). The watershed event was the enactment of the Airline Deregulation Act (ADA) of 1978 in the United States (US). After the ADA went into effect, airlines in the US have been given complete freedom to enter into or exit from any domestic routes without restrictions. Additionally, the flight frequency, the number of seats offered in the market, the airfares charged and the seats allocation of each airfare class on a particular flight can also be determined by each airline itself (Odoni, in Belobaba, 2009).

To match the growing trend of deregulation, the European Union (EU) launched Three Aviation Liberalisation Packages which took ten years from 1987 to 1997 to gradually liberalise the aviation market of Member States. Full cabotage was implemented on 1 April 1997, since then all nine freedoms ${ }^{1}$ were allowed for EU carriers within the EU market (plus Norway and Iceland) (Button and Stough, 2000; Chang and Williams, 2001). Consequently, the EU became the most liberalised region in the world. Any airline with a valid Air Operators Certificate can operate within the EU at market-determined prices (Gillen and Lall, 2004). In addition, the enlargement of the EU in 2004 extended the Single Market to ten new member states.

\footnotetext{
${ }^{1}$ The definitions of nine freedoms are described in Appendix A
} 
In China, the airline industry used to be heavily regulated: all aspects of the industry such as market entry, route entry, the frequency, fare levels and aircraft purchasing were tightly controlled by the Civil Aviation Administration of China (CAAC) (Zhang and Chen, 2003). Since 1997, China's airline industry started to enter into a period of deregulation, consolidation and privatisation. In 2002, nine CAAC-controlled airlines were consolidated into three groups around Air China, China Eastern and China Southern. In 2004, the market was partially deregulated with the establishment of five privately owned airlines. By the end of 2008, 14 new scheduled passenger airlines were established (Lei and O'Connell, 2011). By 2012, the domestic market has been greatly opened up; airlines have gained much greater freedom in route entry, and are able to set the price at the market-determined level.

Aviation deregulation in the US, Europe and China saw the explosion of airline mergers which have resulted in the increase in the market share of individual airlines at the airports, especially those major airlines at their hub airports. This has raised the concerns as to whether high concentration ${ }^{2}$ would lead to substantial monopoly power in the airline industry. How does airport dominance ${ }^{3}$. affect an airline's pricing power? The answer to this question is critical to regulators as well as practitioners in the air transport industry. Borenstein (1989) argued that price premiums are derived from domination and concentration at both airport and route market levels. However, the studies by Evans and Kessides (1993) and Hofer et al (2008) concluded that substantial pricing power is likely to be conferred by airport-related drivers more than routerelated drivers. So far, most studies on airport dominance either focus on the

\footnotetext{
${ }^{2}$ Market concentration is the extent to which a relatively small number of firms account for a relatively large percentage of the market. It is a useful economic tool which reflects the degree of competition in the market.

${ }^{3}$ As to airline industry, market dominance conventionally refers to the airline having the largest market share at an airport or on a route, both in absolute and relative (compared to the second one) terms.
} 
entire airport network (Borenstein, 1989; Abramowit and Brown, 1993), or on hub-to-hub markets (e.g. Vowles, 2006). It is not well understood whether dominating a hub airport has the same effect on airline pricing as dominating an airport which is not operated as a hub for the focal airline (hereafter termed "non-hub airport"). Another gap in the literature is that few studies have explicitly examined the relationship between airport dominance and prices from the market segment perspective. It is well known that passenger mix is an important factor affecting hub premiums (Lee \& Luengo-Prado, 2005), and hub premiums are mainly contributed by relatively price-inelastic business travellers (Berry et al., 1996), however, no published studies have quantified the effects of airport dominance on airline pricing behaviours in these two distinctly different market segments, i.e. economy class market and premium class market.

\subsection{Aim of the Thesis}

The aim of this thesis is to analyse the effects of airport dominance on airline pricing power in the Chinese domestic market. More specifically, this study aims to develop fixed-effect panel data models to assess the impact of airport dominance on airline pricing power and to ascertain whether there are hub premiums in the Chinese domestic market. The reason to choose China as a case study is because previous work mainly focuses on the fully deregulated markets such as the US and Europe, where airlines dominating a market and operating in concentrated, oligopolistic markets may earn substantial premiums; what remains unknown is how such effects change when a country evolves from a tightly controlled regime to a deregulated market. China represents an interesting case. It has experienced exponential growth in air traffic with an average growth rate of $17 \%$ per annum since 1978. By 2005, China has become the second largest aviation market in the world, only behind the US. Using China as a case study, thus, provides much needed insights into this fast growing market in a transition economy. 


\subsection{Thesis Structure}

The remainder of this study is organized as follows. Chapter 2 outlines the previous studies on airport dominance and hub premiums. Chapter 3 provides background information regarding the deregulation and consolidation in the Chinese domestic market. Chapter 4 summarizes the methods and data used for this study and discusses the econometric issues. Chapter 5 presents the estimation results while Chapter 6 concludes the thesis. 


\section{Chapter 2 Airport Dominance and Airline Pricing Power}

Since the deregulation of the US domestic aviation market in 1978, concerns on market power in the airline industry have attracted longstanding attention from governments and academics alike. A potential source of market power is derived from major carriers' move from "point-to-point" service to "hub-andspoke" operation. Such shift has increased the level of market concentration at hub airports, hence, "hub premiums" have become one of the most debated topics in the airline industry. This chapter reviews the literature regarding airline pricing power and hub premiums. Section 2.1 discusses the determinants of airline pricing. Section 2.2 looks into the airline market power and hub premiums. Section 2.3 reviews some empirical studies in the European market in addition to the literature based on the US market. Finally, Section 2.4 summaries this chapter.

\subsection{Determinants of Airline Pricing}

Bailey and Panzar (1981) were among the first to develop price equations to assess the effects of competition on fares. Since then, many studies have employed price equations to examine price determinants in the airline industry. These studies include those that focused on the effects of market structure on airline pricing (Kim and Singal 1993; Leahy 1994); the effects of hub-and-spoke networks on pricing (Brueckner et al. 1992; Vowles, 2006); the effects of the low-cost carriers competition on pricing (Hofer et al., 2008); and the effects of airline alliances on pricing (Brueckner and Whalen 2000; Brueckner 2003). In these studies, the price equation, which is estimated without knowing actual cost information, is regarded as a reduced-form derived from a structural model. The implicit cost information is inferred from cross-sectional variations in prices and product attributes (Bresnahan, 1989). Technically, a reduced-form price equation is considered to be derived from a system of equations representing cost (thus supply) and demand at the market clearing equilibrium condition, 
where the market refers to air-passenger route market. Generally, the supply factors include frequency, aircraft size, load factor, route characteristics (e.g. non-stop or connecting route) and distance. The variables measuring demand side include income, population, tourist or business travellers orientation of the origin and destination cites and other market characteristics (e.g., hub airport, slot-controlled airport, and multiple airports) (Chi and Koo, 2009).

In addition to supply and demand factors, it is found that market structure plays an important role to determine the airfares. Key variables include market dominance, market concentration and airline competition (e.g., low-cost carrier (LCC) competition, full-service airlines (FSA) competition). Several studies demonstrated that airfares are higher in more concentrated markets (e.g. Granham, Kaplan and Sibley, 1983). Moreover, Borenstein (1989) showed that market share of single carrier will contribute to its market power which is not shared by other carriers in the same market. A variety of studies have shown that the contestability hypothesis which states that the presence of competition is unimportant in fare determinant if the market allows free entry and exit (see Bailey and Panzar, 1981), does not appear to hold for the airline industry.

\subsection{Airline Market Power and Hub Premiums}

As discussed previously, it is generally believed that market dominance and market concentration are the main sources of airlines' market power. Numerous studies found that airlines dominating a hub airport are capable of exercising market power, charging higher prices to passengers, which is so called "hub premiums" phenomenon (e.g. Levine, 1987; Borenstein, 1989; Berry, 1990; Evans and Kessides, 1993; Morrison and Winston, 1995; Berry et al., 1996; Lee and Luengo-Prado, 2005; Chi and Koo, 2009). Having said that, it is worth highlighting the facts that the definitions, or measures, of "hub premiums" are not consistent across a variety of studies. In some early studies, hub premiums refer to the mark-ups of average fare at a concentrated hub airport 
comparing to average fare at un-concentrated airports (e.g. GAO, 1990; DOT, 1990). Whereas, in other studies, the hub premiums refer to price mark-ups charged by the dominant airline as opposed to other airlines without airport dominance. An illustration of hub premium components by Hofer et al. (2004) visualizes the different levels of definition as shown in Figure 2-1.

Figure 2-1 Illustrative components of hub premiums

illustrative Components of Hub Premiums

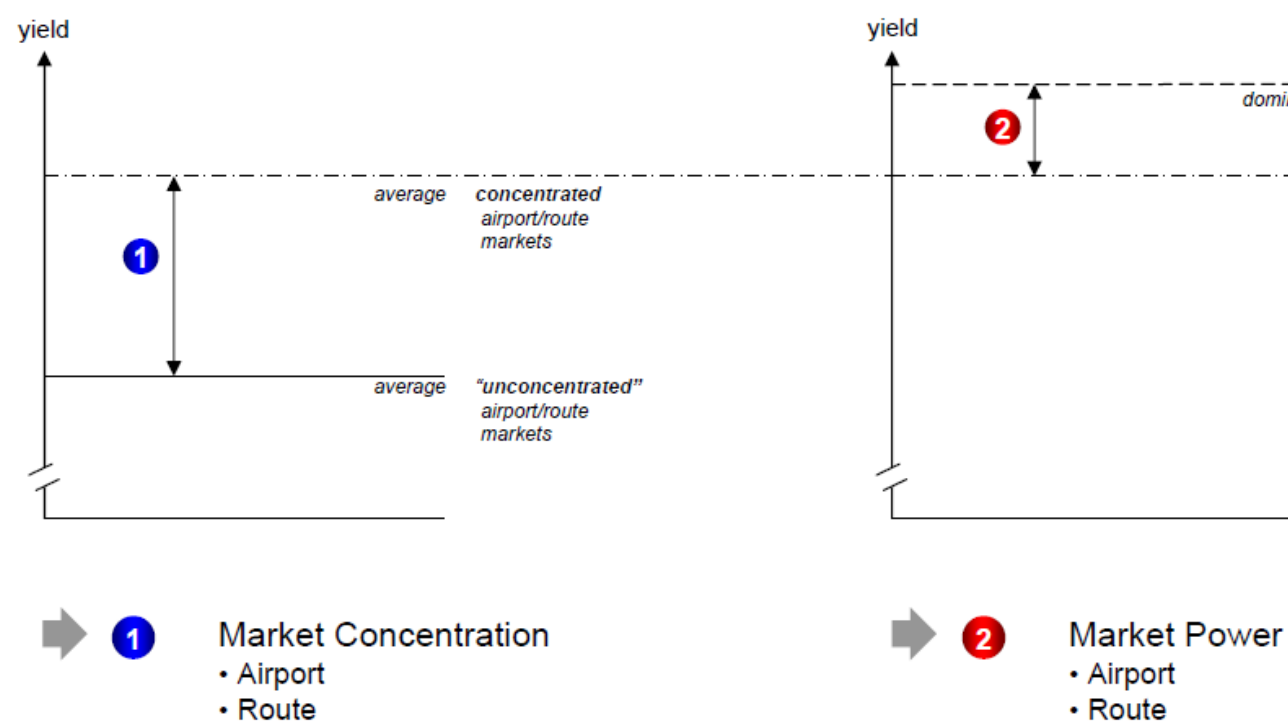

Source: Hofer et al. (2004)

The literature on hub premiums has continuously evolved in the past few decades. These studies have provided us with comprehensive understanding of how various market forces interact in determining airline pricing. The literature is structured into three sub-sections based on the different stages of understanding of the phenomenon of hub premiums. Each stage is discussed in detail in this Section. 


\subsubsection{Stage I: Testing the theory of contestable markets}

Extensive investigation of the effects of market structure on airfares has started by testing the market contestability hypothesis. The observed trend towards concentration immediately raised policy concerns on the industry's tightening structure of supply and the potentially consequent negative effects for market performance. In economics, the concept of contestable market refers to a market served by a small number of firms that behave competitively because of the existence of potential new entrants (Baumol, 1982). The contestable market theory holds that even in the situation of monopoly or oligopoly, the incumbent firms will behave in a competitive manner when there is a lack of barriers, such as government regulation and high entry costs, to prevent new entrants from penetrating the market, leading the market to be characterized by competitive equilibria. A perfectly contestable market has three main features no entry or exit barriers, no sunk costs, and the access to the same level of technology.

Several studies believed that the inherent competitiveness of the airline industry, right after deregulation, suggested that the airline market exhibited a high degree of contestability (Bailey and Panzar, 1981; Bailey and Baumol, 1984). If the idea of perfect contestability holds, the concentration should have no effects on airfares, because the price would already be at their competitive levels, equalling the marginal costs. The views are justified by the assertion that under deregulation, airline entry and exit are characterized by relatively low costs. Hence the threat of potential competition could put pressure on the exercise of market power by the incumbent carriers. Moreover, few of the costs are sunk, because aircrafts can easily be redeployed from one route to another.

However, an econometric analysis using the fare data in late 1980 and early 1981 by Graham et al. (1983) rejected the hypothesis that fares are independent of market concentration. Shepherd (1984) questioned the 
assumption of "ultra-free entry" and challenged its applicability in the airline industry. Morrison and Winston (1986) also suggested that perfect contestability is not present in the airline industry because carriers require time and must absorb sunk costs to obtain gate space and establish patronage which is particularly difficult when competing against carriers that offer frequentflier programs (FFPs). By the end of 1980s, it has widely recognised that perfect contestability theory does not hold for airline pricing. There is convincing evidence that the airline industry has substantial barriers to entry on account of the existence of a variety of entry constraints and methods of product differentiation (see Graham et al., 1983; Morrison \& Winston, 1987; Hurdle et al., 1989).

\subsubsection{Stage II: Observing the "hub premiums"}

Graham and Kaplan (1982) were among the first to discover the phenomenon that "fares in monopoly markets are higher than those in relatively unconcentrated market". In 1990, the General Accounting Office's (GAO) conducted a widely cited study which was the first to quantify the hub premiums. In this report, the yields (average revenue per passenger-mile) for trips originating at 15 dominated hub airports were compared to the yields at 38 unconcentrated airports in 1988. This simple comparative analysis concluded that yields at hub airports were $27.2 \%$ higher. This study used the Department of Transportation Data Base 1A (DB1A), a 10\% sample of all tickets originating in the US served by US carriers. The database contains information on total price paid, carrier, origin, destination, class of travel and routing, consisting of millions of observations collected on a quarterly basis. It is one of the most comprehensive airline ticket datasets and has been widely used by most studies in airline pricing. The definition of "dominated hub" in GAO's (1990) study is an airport that $60 \%$ of all enplanements were taken by one carrier, or $85 \%$ were taken by two carriers. Some argued that a hub should not be defined based on proportion of total passengers carried by an airline, but rather should be based on some threshold of passengers making connecting travel. 
The US Department of Transportation (DOT) conducted a similar study in the same year, examining these two groups of airports while controlling for route distance. The DOT's (1990) study found an average hub premium of $18.7 \%$ for airports dominated by one airline, and the premium of $8.9 \%$ for airports dominated by two airlines. The definition of a concentrated hub is an airport with more than $75 \%$ of enplanements controlled by one carrier, which is different from that of the GAO study (1990).

However, the methodology employed by the GAO (1990) appears to be too simplistic. It implicitly assumed that trips taken from these two groups of airports were identical, not taking into account of flying distance, the number of plane changes, passenger mix (business travellers ratio), carrier identity, unitcost differences, and frequent flyer programmes. Similar analyses that controlled for some of these factors were carried out and found more modest levels for the hub premium (DOT, 1990; Morrison and Winston, 1995). As mentioned previously, when controlling for the distance, DOT (1990) study indeed found a lower hub premium. Since the US hub airports are generally located centrally, routes originating from hub airports are typically shorter than non-hub routes. While the cost per mile is higher for shorter routes because the fixed costs such as landing fees do not vary with the stage-length of a flight. Hence a longer route can spread such fixed costs over distance. It means that the observed higher fare level may be owing to the higher costs rather than concentration effects. Another important factor that may impact average fares paid for hub market is higher proportion of business travellers with relatively inelastic demand. Additionally, scarcity rents generated by limitation of slots and gates in congested major airports may be another source of premiums. In another word, without controlling for these factors, any observed hub premiums may simply be due to the inherent characteristics of hub markets, rather than market dominance. 
Morrison and Winston (1995) updated the GAO study using similar approach but attempting to control for a number of other factors influencing the price. They compared the yields at 15 concentrated hub airports as opposed to 27 unconcentrated airports using DB1A data from 1978 to 1993. The analysis revealed that hub premiums ranged from 4\% to $10 \%$ between 1978 and 1993 . Notably, they found a significantly lower hub premium of $5.2 \%$ in 1993 in contrast to the result of $33.4 \%$ estimated by GAO's methodology. The $28.2 \%$ deviation was decomposed into several aspects. Distance and the number of plane changes reduced the estimated premium by $18.6 \%$; carrier-specific effects made a $4.6 \%$ difference; correcting for FFPs and passenger mix each removed $2.5 \%$ off the premium respectively. It was found that some carriers tended to charge higher prices not only on route originating from the hub airports but also for the whole network comparing to market average price level, thus the carrier-specific characteristics of hub carriers should be regarded as a service-quality premium, or brand premium, rather than the effects of dominance. Similarly, higher proportion of non-stop routes originating from hub airports may result in higher average fare at airport level, which should reflect as service-quality premium as well. In conclusion, despite the absence of robust econometric methods, Morrison and Winston (1995) provided very useful insights into the sources of hub premiums.

In summary, studies at this stage focused on pooling the data for all airlines together to investigate the degree to which average fares differed at hubs versus at other airports. However, they made no distinction between dominance and concentration effects. Also, the different impacts from airportrelated and route-related drivers were still ambiguous. This led researchers to employ more sophisticated econometric models and more comprehensive dataset at the carrier and market level to disentangle the sources of market power. 


\subsubsection{Stage III: Disentangling the sources of market power}

Hofer et al. (2008) argued that the monopoly rents of airlines stem from different drivers. First, there is a need to distinguish airport-related and route-related drivers of pricing power. Moreover, market dominance and market concentration should be treated as two different dimensions of oligopolistic competition. Studies at this stage focus on comparing the prices of a network carrier's hub markets versus the prices of all other airlines in otherwise similar markets. The purpose is to distinguish route and airport characteristics as sources of potential pricing power by controlling for structural differences between these two types of markets.

Borenstein (1989) was one of the first authors using sophisticated econometric approach to estimate the effects of route and airport dominance and concentration on prices. His work is regarded as one of the most influential studies in hub premium debates. He found that the dominance and concentration at the route level as well as at the airport level are principal determinants of price premiums of an airline, after controlling for a number of variables, such as flight frequency, distance, numbers of stops, unit-costs, carrier identity and airport constraints. He argued that frequent-flyer programs (FFPs), travel agent commission override programs (TACOs), and corporate discount programs (CDPs) are the main causes of hub premiums. Control of scarce resources like gates and slots by incumbent airlines is also an entry barrier for new entrants. It is worthy noticing that Borenstein's (1989) definition of hub premiums differs from those in the aforementioned studies. Basically, Borenstein (1989) estimated the hub premium charged by the dominant airline relative to airlines without airport dominance, while the previous studies estimated the degree to which the average fare at a concentrated hub airport differs from average fare at un-concentrated airports, which is not specific to the dominant airline. 
Additional evidence on hub premiums was provided by Evans and Kessides (1993) who concluded that the effects of competitiveness on price are more associated with airport characteristics rather than route features. After controlling inter-route heterogeneity in price which has been omitted in Borenstein's (1989) study, Evans and Kessides (1993) estimated a reduced form fixed-effect price model. They found that substantial pricing mark-ups are derived from an airline's dominance at an airport rather than at the route level. They further revealed that the airline's perceived pricing power at route level is actually conveyed through its control of airport. Airport and route concentration also plays a role in explaining price premiums but the effects are relatively small compared to airport dominance. Their findings are partially supported by Hofer et al. (2008) who confirmed that airport market share and airport concentration contribute to largest part of price premiums while the impacts of route market share and concentration on price are much smaller.

A limitation associated with the above studies is that the different market segments of economy and premium class have not been separated. The reason is probably due to the lack of reliable data. Most of the empirical studies on pricing behaviour in the US airline industry have been conducted relying on the US DOT's Origin and Destination Survey, which is a $10 \%$ random sample of all tickets that originate in the US and on US carriers. Most researchers prefer to use restricted coach fare because the premium fare classification is defined by carriers and may not follow the same standard. Moreover, some apparent mistakes occur in premium fare data. For instance, JetBlue as a low-cost carriers report all their tickets as first-class. Borenstein (1989) attempted to analyse the pricing effects focusing on different market segments by examining the 20th, 50th and 80th percentile fares. However, the proportion of leisure and business travellers may vary widely across markets, thus the same percentile fare may represent different passenger mix across various markets. For instance, the 80th percentile fare may represent business passengers in some markets whereas leisure traveller in others. Hence, aggregating the same 
percentile fare data may risk from mixing the effects for different market segments. Despite problems in the data, Borenstein (1989) still found that airport market share has more profound impact on the high priced market than on the low priced market.

Because of data constraints, it is unfeasible to test the pricing effects of different cabin classes on airport dominance using reduced-form price equation. Berry et al. (1996) developed a utility function based on discrete choice model of demand, to estimate the differential willingness to pay for different air travel features of leisure and business travellers. Their results are consistent with the existence of two very distinct types of passengers. One is with normal attributes of a leisure traveller, which is high price sensitivity, low willingness to pay for frequent flyer features, low willingness to pay for high frequency, and low disutility from connecting flights. The other is with strong business traveller flavour, which is just opposite of the former. These estimates are the key to uncover the ability of hub carriers to increase their mark-ups in hub originating flights. They concluded that the dominant hub carrier's ability to charge higher fares is restricted to the tickets that appeal to relatively price-inelastic business travellers, who favour the origin-hub airline, and are willing to pay an average premium of $20 \%$. However, these high prices do not provide a "monopoly umbrella" to other non-hub airlines.

Similar conclusions were obtained by Lee and Leungo-Prado (2005). They used the fare data of different cabin classes, namely, restricted coach fares and premium fares. The premium fare group in their study includes $82 \%$ unrestricted coach fare and $18 \%$ business and first-class fare. They found that some carriers extract additional hub premiums from premium fare class passengers. After controlling for passenger mix, the average hub premium at major US hubs is reduced. However, instead of developing separate models for these two different markets, they only used premier dummy variable to capture the effects 
of passenger mix. In doing so, they failed to measure the effects of airport dominance on pricing in these two distinctive market segments.

There are some other studies attempting to control for various factors affecting airfares. The Air Transportation Association study (Simat, Helliesen, and Eichner, 1989) examined the factors determining fares, with an emphasis on concentration, using data from 30 hub airports and 30 non-hub airports. Their estimation results are in contradiction to most previous studies of airline pricing in that concentration have no significant impact on fares. However, Abunassar and Koford (1994) criticised that the regression model in the above study was mis-specified as a number of important variables have not been included into the model. Furthermore, there is evidence of multicolinearity which cast doubts on the validity of the results. Abunassar and Koford (1994) then estimated a revised version of the regression model that corrected for those problems. Their estimation indicated that dominance of an airport resulted in a $10 \%$ higher fares, relative to the un-concentrated airports.

In addition to the conventional approach that examines the hub premiums by evaluating absolute fares paid, an alternative approach was adopted by some other studies, comparing the differences in market share or yields on flight to and from a hub to test for the impact of airport dominance. Borenstein (1990) showed that an airline with a dominant position at an airport has a larger share of the overall originating traffic, and thereby also has a larger share of any market originating at the dominated hub. A similar methodology was employed by Dresner and Windle (1992). They controlled for distance and airport-level characteristics when comparing yields on flights that originate from hubs to yields on flights that are destined to hubs. They found that flights from a hub have higher yields than those to a hub. 
Before moving to the next Section, one more issue regarding the evolution of literature should be mentioned is that LCCs are found to play an important role in reducing hub premiums in the US domestic market. A number of studies assessed the extent to which LCCs affect the network carrier's ability to exercise their market power (e.g. Morrison, 2001; Hofer and Dresner, 2008; Brueckner et al., 2013). However, LCC competition is very limited on hub originating routes in the Chinese domestic market. Hence, the review of literature on the effects of LCCs' on hub premiums is not included in this thesis.

\subsection{Empirical Studies for European Market}

The literature review discussed previously was completely based on the US domestic market, however, as Tretheway and Kincaid (2005) pointed out that results obtained from the US studies cannot be simply extended to other markets. Considering the varied market structure characteristics, different progress of deregulation, diverse policy environments of the airline markets throughout the world, it would be worthwhile to examine whether the findings would apply elsewhere.

Apart from China - the market on which my empirical research is based, Europe also plays an important role in the global airline industry in terms of is its size. In contrast to the 'big bang' style deregulation of the airline market in the US, liberalization in the EU took 10 years to complete, as a result of three "packages" of measures in 1987, 1990 and 1992, respectively. The initial deregulation of fare came with the first package in 1987 and all remaining restrictions on designation, market access and capacity were removed for intra-EU flights following the implementation of the third package (Odoni, in Belobaba, 2009). 
Marin (1995) was considered to be one of the first authors to discuss the hub premium issue in the European context. He analysed the impact of liberal bilateral agreements on several European air routes in terms of price competition and market structure by estimating a market share model and a price model in a regulated environment (all routes in 1982 and some routes in 1989) and a deregulated environment (some routes in 1989). He suggested that for European markets, airport dominance effect on airfare is absent in regulated environments, and is significantly negative on deregulated routes, which is opposite to the findings in the US. The negative effects of airport dominance on price indicate that European carriers tend to exploit the cost reducing effect of airport presence in order to compete in prices. The difference between this result and previous US studies may be explained by the significant differences in market power related factors. For example, during the sample period of Marin (1995)'s study, Computer Reservation Systems (CRSs) were shared by multiple European carriers while belonging to individual single carrier in the US. Moreover, FFPs almost did not exist in Europe and the hub-andspoke system had not yet prevailed as it had in the US. As a result, hub carriers in Europe may find it difficult to improve the perceived quality and exercise market power through airport dominance.

Following the implementation of the three packages, Lijesen et al. (2001) examined the hub premium of European carriers by relating airfares to distance, route $\mathrm{HHI}$, and a few airline dummies using unrestricted economy class fare data in February 2000 obtained from internet webpages of Travelocity. Sample data included ten European origins, with eight of them being the intercontinental hubs for their home carriers. The results revealed that price markups existed on flights to or from hub airport. The average fares of Lufthansa, Air France and Swissair were 15\% higher than other airlines in the sample, everything else being equal. At least some of these premiums can be attributed to market power. These findings are consistent with those found in the US domestic market. However, the study by Lijesen et al. (2001) suffers from serious data deficiency. Fare data obtained from internet websites such as 
Travelocity were not representative of the average fares as the authors had no knowledge as to how many tickets were sold at given prices. It is well known in the airline industry that airlines frequently change the prices to balance supply and demand. Furthermore, Lijesen et al (2000) failed to control for a lot of other factors such as airport dominance and concentration, population and income at endpoint cities; all these factors are likely to have significant effects on airfares.

Giaume and Guillou (2004) followed Borenstein's (1989) approach, and regressed the price on market structure variables including market share and $\mathrm{HHI}$, as well as some controlled variables, for different carrier-route pairs, using cross-sectional data on intra-European routes. They found that concentration has a significant negative effect on airfares in the EU market, which is opposite to the empirical results for the US market. Guaume and Guillou (2004) explained the discrepancy by the differences of market structure characteristics of these two markets. They argued that carriers serving the European market have high inequality of market share, where major airlines take up the majority of market share, leaving smaller carriers with no choice but to compete on prices. But the results and methodology of their study were questioned by Piga and Bachis (2007). One of the arguments was that LCC variable was excluded in the model. Given the fact that LCCs controlled substantial market share on the intra-European routes, excluding this variable may lead to biased results.

Piga and Bachis (2007) examined the effects of origin airport dominance as well as route dominance on airline pricing behaviour in the UK-Continental Europe market using panel data analysis. In their study, fare data were collected from airlines' websites. Their estimation results indicated that in airport-pair route market, market share has significant positive relationship with airfares, but the conclusion does not hold for city-pair market. Furthermore, dominating an airport is conducive to pricing power. However, they found that LCCs in Europe tend to set higher fares in other airports rather than in their primary hubs. Since 
they only include dummy variable of hub airports for LCCs in the model, the hub dominance effects for the whole market is unable to be evaluated.

\subsection{Summary}

This chapter reviews the relevant literature on hub premiums in both US and European markets. Research in the US in the 1980s focused on testing the theory of contestable markets. A number of studies have confirmed that perfect contestability theory does not hold in the airline industry, and price mark-ups did exist given the existence of potential competition. Then, studies moved to the identification of hub premiums. A number of research conducted by US government agencies (e.g. DoT and GAO) as well as academics (e.g. Morrison and Winston (1995) confirmed the existence of the phenomenon of hub premiums. After that, studies at the next stage focused on disentangling the sources of market power making distinction between the effects of airport dominance and concentration as well as airport-related and airport-related drivers of pricing power. Despite different methods of measurement, a variety of studies come to the same conclusion that airport dominance and concentration lead to higher airfares. Moreover, airport dominance plays an important role in determining an airline's pricing power whilst the effects of route dominance and market concentration are a bit controversial. Furthermore, the effect of airport dominance on pricing is probably more reflected in the business travel market.

Compared to the abundant studies on hub premiums in the US, research on this topic in the context of Europe is somewhat limited. This is mainly due to the difficulty of obtaining reliable data. The four studies discussed in Section 2.3 all suffered from data deficiency, due mainly to the inability to obtain reliable fare data. Having said that, reviewing of the studies in the European market still provided some interesting insights into the issues of hub premiums. Marin (1995) found that market dominance and concentration have negative effects 
on airfares, which is opposite to the findings in the US domestic market. By contrast, Lijesen et al (2001) revealed that hub premiums exist on flights to or from hub airports. The controversial results may due to the different periods focused by the authors; Marin (1995) focused on the period before the full implementation of the third package, while the research by Lijesen et al (2001) was focused on the fully liberalised European aviation market.

Review of the literature also reveals that there are some limitations in the previous studies. First, few studies have quantified the effects of airport dominance on airline pricing behaviour in two distinct market segments, i.e. economy class market and premium class market. Second, most of the studies are conducted based on the cross-sectional analysis, which may risk leading to biased results as this approach is incapable to control for the specific carrierroute effects (Evans et al., 1993). Third, most of the studies focus on the airport dominance effects making no distinction between hub airports and non-hub airports, so it remains unknown whether dominating a hub airport has the same effect on airline pricing as dominating a non-hub airport.

In addition, the study in the context of Europe shows that when a market was evolving from partial to full deregulation, the pricing behaviour of airlines was very different. Therefore, it would be interesting to investigate the relationship between those market structure factors and the airline pricing power in a market moving from a tightly controlled regime to a deregulated market.

This thesis aims to address those limitations identified in the previous literature with an empirical study based on the Chinese domestic market. Before we proceed to the econometric analysis, the next chapter provides an overview of deregulation, airline consolidation and hub airport development in China. 


\section{Chapter 3 Deregulation, Airline Consolidation and Hub Airports in China}

\subsection{Deregulation and Airline Consolidation in China}

China has experienced exponential growth in air traffic with an average growth rate of $17 \%$ per annum since 1978 . By 2005, China has become the second largest aviation market in the world, only behind the US. The Chinese government has played a major role in shaping its air transport industry amidst a fast transforming economy (Lei and O'Connell, 2011). In the domestic market, two particularly important decisions were made: airline consolidation and opening up of domestic aviation market. In 2002, nine CAAC-controlled airlines were consolidated into three groups around Air China, China Eastern and China Southern. The consolidation resulted in a significant restructuring of the Chinese aviation market and created three equally sized and spatially balanced airline groups. Air China, China Eastern and China Southern each has a primary hub in Northern China (Beijing), Eastern China (Shanghai) and Southern China (Guangzhou), respectively.

After the 2002 airline consolidation, the Chinese government further deregulated the domestic market; carriers have been given great freedom on route entry and are able to set airfares at market determined prices. Approval procedures were simplified, and applications were rarely rejected (Lei and O'Connelll, 2011). As airline consolidation was completed in 2005, the CAAC removed its restrictions on private investment for domestic airlines. Lei and O'Connell (2011) reported that by the end of 2008, the CAAC approved 14 new scheduled passenger airlines, with the majority of them being controlled by domestic private investors. However, constraints remained as many of these new airlines were prohibited from serving lucrative routes which were dominated by the extensive route networks of the Big Three incumbents. Still, the entry of the new carriers has intensified competition in the domestic market. 
Further consolidation continued when China Eastern took over its largest rival, Shanghai Airlines in 2009, and Air China gained control of Shenzhen Airlines in 2010.

\subsection{The Development of Major Hub Airports in China}

The noticeable consequence of airline consolidation is the development of huband-spoke network by Big Three with particular efforts put on strengthening the dominant positions at respective hub airports. The operation of hub-and-spoke networks can affect both demand and cost of airlines. Costs can go down due to higher traffic density in hub-and-spoke operations than in point-to-point services (Caves et. al., 1984). In addition, since there are more flights available between the origin and destination (OD) cities over a hub-and-spoke network, service quality may be improved as more travellers can find a flight at their desired departure time. Furthermore, a hub-and-spoke network allows an airline to serve many additional city-pairs when new spoke routes are integrated into the existing network (Lei and O'Connell, 2011). Since long distance or intercontinental travels are costly, the development of an extensive hub-and-spoke network is important to an airline; such a network can feed traffic from spoke markets in addition to local travellers at the hub city. Another benefit of huband-spoke networks is that an airline may be able to charge a higher price for flights out of its hubs, a benefit referred as "hub premium" in the literature (e.g. Borenstein, 1989; Dresner and Windle, 1992; GAO, 1990). Because of these benefits associated, many airlines have developed hub-and-spoke networks. Fu et al. (2010) noted that major US carriers strategically plan their networks to strengthen their dominance in existing hubs and to expand continental market coverage. Such a development strategy is often achieved through airline mergers and acquisitions. Consequently, network carriers often control substantial market shares at their hubs. 
It is worth highlighting that in this study only direct traffic has been taken into account. This is because that Chinese domestic market is dominated by direct flights. Paleari et al (2010) noticed that in 2007, direct flights account for $80 \%$ of all seats offered in China, while it only accounts for $60 \%$ and $57 \%$ in the US and Europe respectively. Furthermore, the connecting traffic ratio at Shanghai Pudong Airport (PVG) and Guangzhou Baiyun Airport (CAN) was only $7 \%$ and $4 \%$, respectively (Fu et al, 2012). Therefore, focusing on the direct traffic data captures the main features of the Chinese domestic market. Another reason to focus on the direct traffic is due to the fact that the main purpose of major Chinese airlines to adopt hub-and-spoke network is to strengthen their international operations (Fu et al., 2012). Major airlines in China do not intend to combine traffic to and from spoke airports via connection at hubs and thereby link small cities to other destinations in the domestic market. Instead, they are keen to consolidate the traffic at hubs to feed their oversea routes. In another word, the hub airports in China are positioned as international hubs rather than domestic hubs. Hence, to study hub premiums in the Chinese domestic market, there is a need to focus on the direct traffic.

Figure 3-1 illustrates the domestic network of Air China (CA) in 2002, 2007 and 2012. It can be seen that the hub status of PEK has been strengthened over time with a growing number of destinations linked to the hub. Comparing the CA's network in 2007 with 2002, it can be found that CA expanded its network to the southwest China following its acquisition of China Southwest Airlines. By 2012, Air China has developed extensive network from its primary hub at PEK (Beijing) covering economically prosperous Eastern regions and major cities in Western China.

Figure 3-1 Domestic network of Air China (CA) in 2002 (Upper left), 2007 (Upper right) and 2012 (Bottom) 


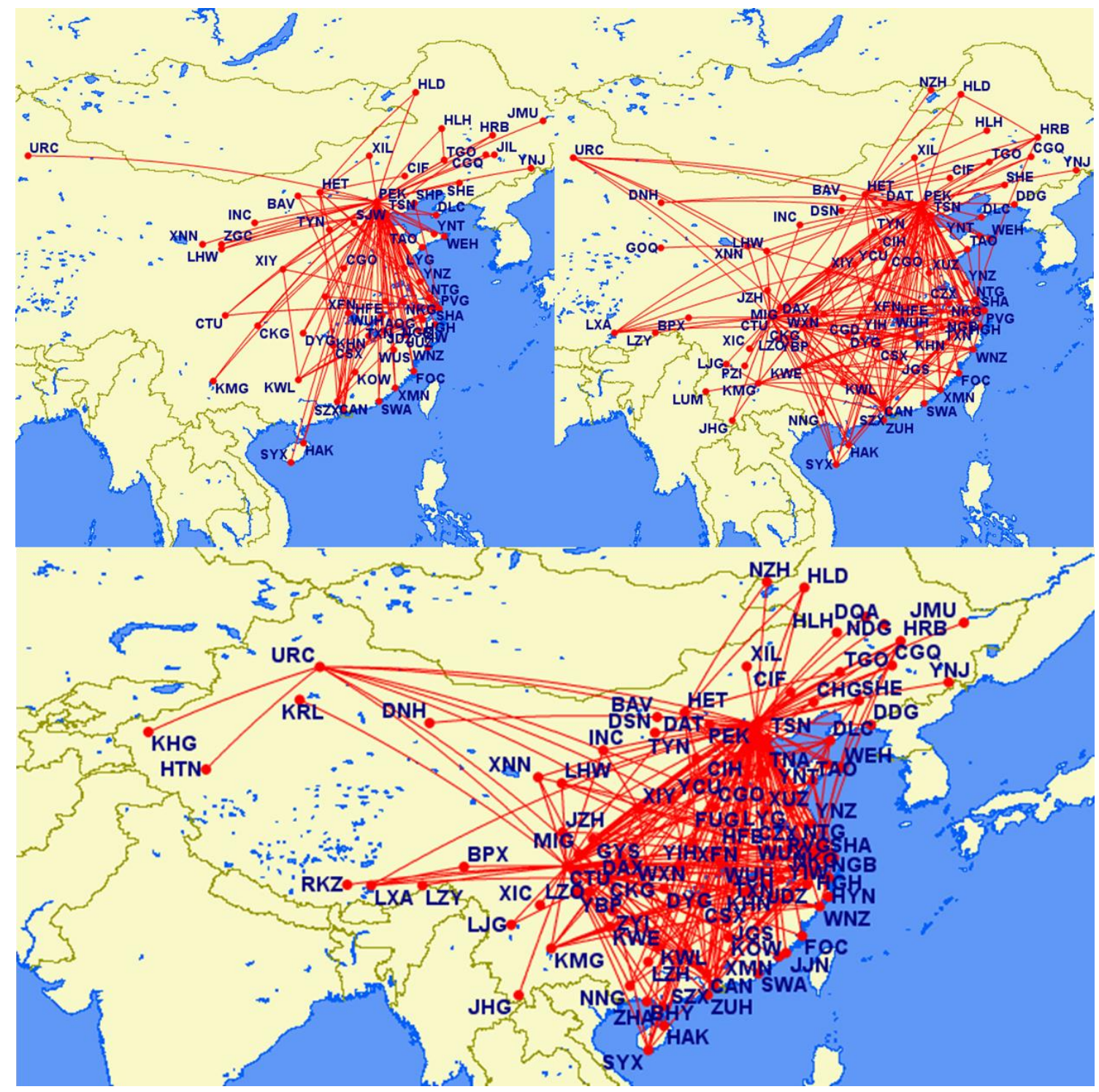

Source: The author, compiled from the OAG database.

Beijing Capital International Airport (PEK) is now the second largest airport by passenger numbers in the world while Guangzhou Baiyun International Airport (CAN), Shanghai Pudong International Airport (PVG) and Shanghai Hongqiao International Airport (SHA) are all among the world's top airports in terms of passenger throughput. These four airports are the most important hubs in China. 
Figure 3-2 Airport market share of the Big Three at their primary hubs: 2002-2012

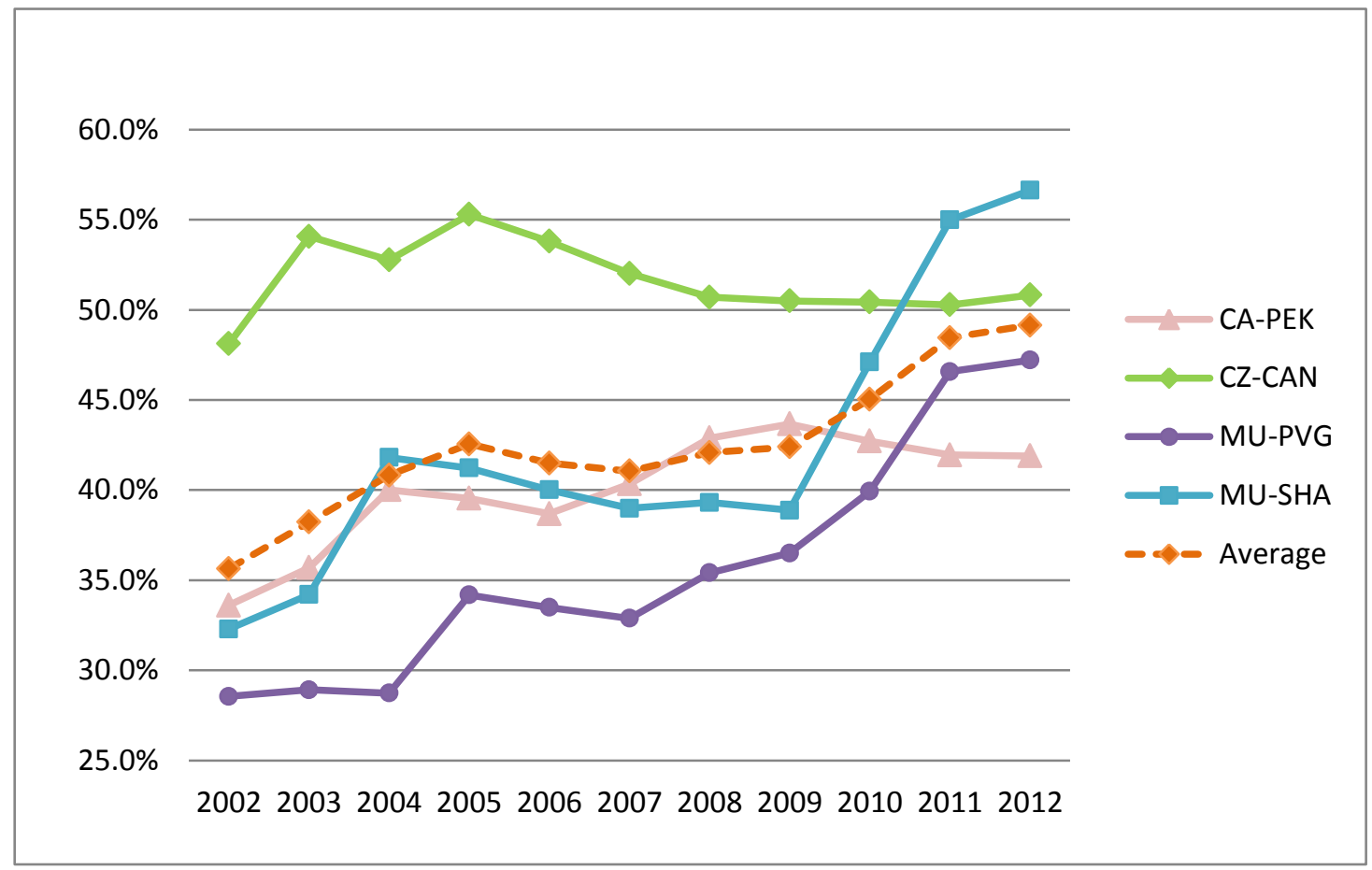

Notes:

1) $\mathrm{CA}=$ Air China; $\mathrm{MU}=$ China Eastern Airlines; $\mathrm{CZ}=$ China Southern Airlines; PEK=Beijing Capital International Airport; PVG=Shanghai Pudong International Airport; SHA=Shanghai Hongqiao International Airport; CAN=Guangzhou Baiyun International Airport

2) The calculation of the market share is based on seat capacity

3) The merger between China Eastern and Shanghai Airlines was completed in June 2010, hence the market share for China Eastern after 2010Q3 at PVG and SHA include the combined market shares of both airlines.

Source: The author, compiled from the OAG Database

Figure 3-2 shows the airport market share by capacity of Big Three at their primary hubs. As it can be seen, in 2002, Air China controlled $33.6 \%$ of share at PEK, while China Southern was responsible for $48.1 \%$ of the market at CAN. Following 2002 consolidation, both airlines have gradually strengthened their dominant positions and the market shares were increased to $41.9 \%$ for Air China at PEK and $50.8 \%$ for China Southern at CAN in 2012. Compared to the relatively modest increase in the market share of Air China and China Southern, China Eastern's expansion at its hub airports was somewhat phenomenal. In 
2002, China Eastern's market shares at its two Shanghai hubs were relatively low: $28.6 \%$ at PVG and $32.3 \%$ at SHA. This was probably due to fierce competition posed by another Shanghai based airline - Shanghai Airline. Following 2002 airline consolidation, China Eastern's market shares at PVG and SHA were increased to $34.2 \%$, and $41.2 \%$ in 2005 , respectively. The acquisition of Shanghai Airlines in 2009 further boosted China Eastern's presence at its hub airports, gaining $47.2 \%$ share at PVG and $56.5 \%$ at SHA in 2012. In sum, consolidation has greatly increased the market share of Big Three at their hub airports.

However, compared with their counterparts in the US where the majors generally controlled $60-75 \%$ of the market at the hub airports, the market share of Chinese major carriers are still relatively low. This is probably due to the fact that airlines and airports are deeply integrated in the US (Fu et al, 2011) while in China, airlines are not allowed to hold greater than $25 \%$ stake in an airport. The intention of such regulation in China is to limit airlines' anti-competitive behaviour resulting from airport ownership. It is not surprising to see that hub airports in China provide favourable terms to non-hub carriers. For instance, with the support of Beijing airport, China Southern has exclusively occupied and operated Terminal 1 since September 2004. At the same time, Hainan Airlines and Shenzhen Airlines gained a solid foothold at China Sothern's hub airport at Guangzhou (CAN). Given that different types of airline-airport relationships in China as opposed to the US, it is rather uncertain whether hub carriers in China are able to replicate the success of their US counterparts to translate their airport dominance into pricing power at the route level.

Figure 3-3 shows that the $\mathrm{HHI}$ at the major airports initially increased after the 2002 airline consolidation and then gradually declined following the opening up of the domestic market in 2005 with the exception of PEK which saw its $\mathrm{HHI}$ relatively stable from 2008 to 2012. Clearly, the evolution of $\mathrm{HHI}$ at the four major airports followed a different pattern from that of market shares because 
concentration is determined by not only the largest firm but also the market share distribution of all the market players. This justifies the need to separate the effects of market share and concentration when studying airline pricing power.

Figure 3-3 HHI of four Major Airports in China: 2002-2012

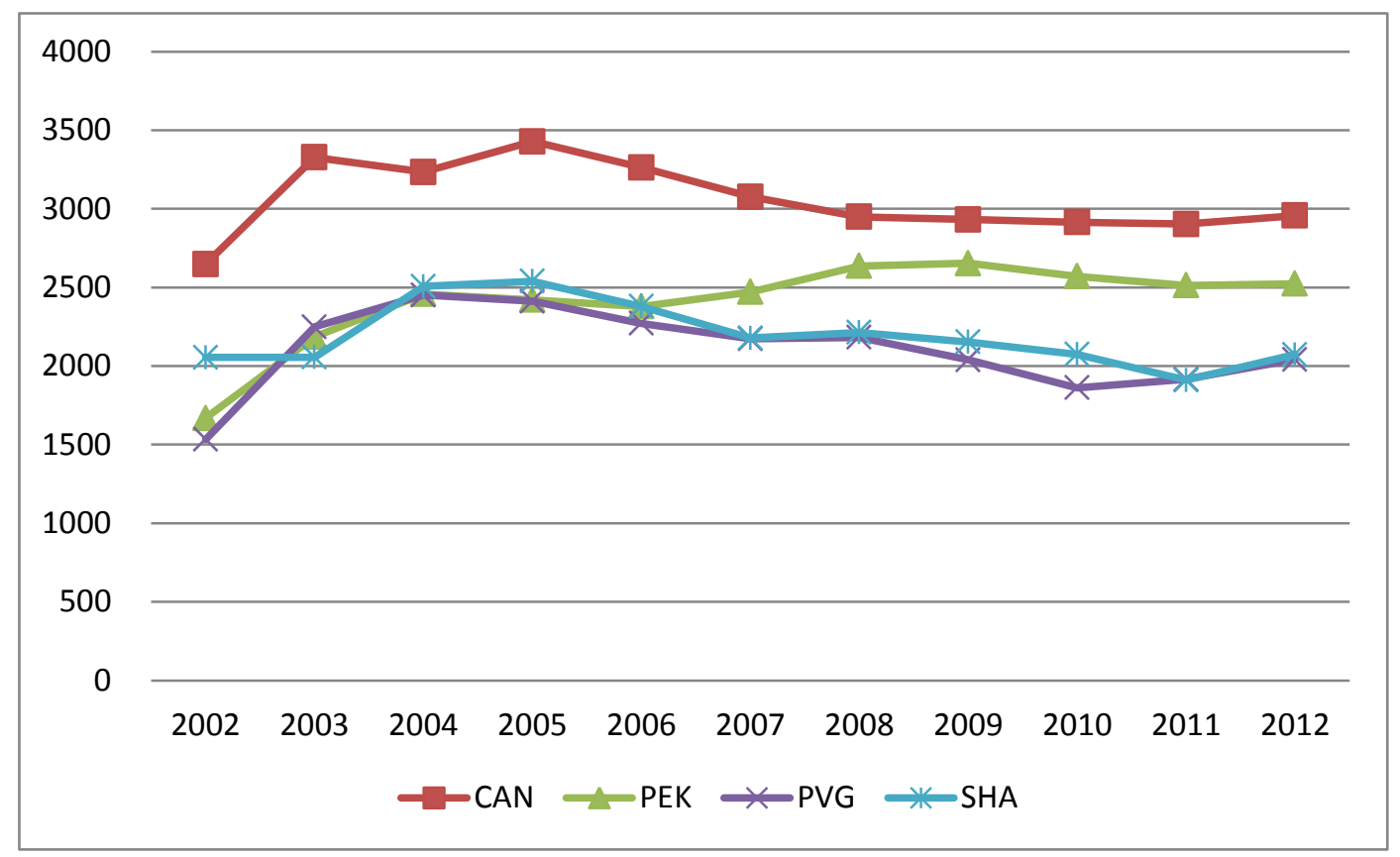

Notes:

1) $P E K=B e i j i n g$ Capital International Airport; $P V G=S h a n g h a i$ Pudong International Airport; $\mathrm{SHA}=$ Shanghai Hongqiao International Airport; $\mathrm{CAN}=$ Guangzhou Baiyun International Airport

2) The calculation of $\mathrm{HHI}$ is based on seat capacity

3) The merger between China Eastern and Shanghai Airlines was completed in June 2010, hence the market share for China Eastern after 2010Q3 at PVG and SHA include the combined market shares of both airlines.

Source: The author, complied from the OAG Database

Another important feature of hub airport market is the composition of passenger mix. Table 3-1 compares the relative percentage of premium passengers carried by the major carriers at their respective hub against the hub airport average. Overall, hub carriers have higher proportion of premium passengers 
than the average of the airports. The results seem to suggest that the hub carriers are more attractive for premium passengers than other carriers who also provide premium products in the same markets.

Table 3-1 Premium passenger percentage comparison between hub carrier and hub airport average level

\begin{tabular}{|c|c|c|c|c|c|c|c|c|c|c|c|}
\hline & 2002 & 2003 & 2004 & 2005 & 2006 & 2007 & 2008 & 2009 & 2010 & 2011 & 2012 \\
\hline CA at PEK & $57.6 \%$ & $68.6 \%$ & $72.4 \%$ & $82.9 \%$ & $65.4 \%$ & $106.2 \%$ & $60.0 \%$ & $67.4 \%$ & $-3.3 \%$ & $20.2 \%$ & $30.9 \%$ \\
\hline MU at PVG & $93.8 \%$ & $18.0 \%$ & $22.1 \%$ & $29.8 \%$ & $36.0 \%$ & $15.3 \%$ & $-5.8 \%$ & $-5.4 \%$ & $37.7 \%$ & $35.4 \%$ & $26.8 \%$ \\
\hline MU at SHA & $19.9 \%$ & $30.0 \%$ & $35.6 \%$ & $35.3 \%$ & $33.5 \%$ & $45.6 \%$ & $49.5 \%$ & $18.0 \%$ & $-52.2 \%$ & $32.9 \%$ & $38.7 \%$ \\
\hline CZ at CAN & $57.5 \%$ & $52.6 \%$ & $47.8 \%$ & $24.1 \%$ & $27.7 \%$ & $31.4 \%$ & $38.8 \%$ & $9.4 \%$ & $-56.5 \%$ & $18.1 \%$ & $26.2 \%$ \\
\hline
\end{tabular}

Notes:

1) 1) $C A=A$ ir China; $M U=$ China Eastern Airlines; $C Z=C h i n a$ Southern Airlines; PEK=Beijing Capital International Airport; PVG=Shanghai Pudong International Airport; $\mathrm{SHA}=$ Shanghai Hongqiao International Airport; $\mathrm{CAN}=$ Guangzhou Baiyun International Airport

2) Percentage of premium passenger is calculated by the number of premium passengers divided by total passengers; relative percentage is calculated by the difference of percentage between the hub carrier and the hub airport average level, divided by the percentage of hub airport

Source: The author, compiled from Sabre ADI Database

Table 3-2 and 3-3 compare average fare per mile (in CNY/mile) for hub carriers and non-hub carriers at the four primary airports in the third quarter of 2002 and 2012 respectively. The results in the economy fare class show that in 2002, the average yields of hub carriers were lower than non-hub carriers at CAN and PEK for all markets. When the market is segmented by distance, different pictures have emerged. In general, the average yields of hub carriers were lower than those of non-hub carriers in the short haul markets, i.e. distance less than 1000 miles. However, hub carriers were able to charge higher prices on routes with distances longer than 1000 miles. This is probably because longhaul routes are more likely to be dominated by major airlines, hence inducing higher prices. Nevertheless, by 2012, fares charged by the hub carriers were 
higher or similar as those charged by non-hub carriers in almost all flight distance segments. In terms of the average yields regardless of the distance, it has become evident that the prices charged by hub carriers were higher than non-hub carriers at all four hub airports. These results seem to suggest that hub premiums exist in China as dominant airlines' increases their market shares at hub airports.

In the premium fare market, hub carriers' average yields were higher than those of non-hub carriers at all hub airports, except for China Southern (CZ) at CAN in both 2002 and2012. The consistent results seem to indicate that the phenomenon of hub premiums is more significant in the premium market as opposed to the economy market. When the premium markets are segmented by distance, some mixed results have emerged. For example, at PVG in 2002, the average yields generated by hub carrier were lower than those charged by non-hub carriers in the 500-1000 miles segment. The situation was reversed in 2012 for the same segment, though the hub carrier's average yields were lower than non-hub carriers in the segments greater than 1000 miles. 
Table 3-2 Comparisons of Average Fare per Mile (Yield) for Flights from Dominant Airports in $3^{\text {rd }}$ Quarter, 2002

\begin{tabular}{|c|c|c|c|c|c|c|c|c|}
\hline \multirow{2}{*}{$\begin{array}{l}2002 \mathrm{Q3} \\
\text { Economy }\end{array}$} & \multirow[b]{2}{*}{$\begin{array}{l}\text { Hub } \\
\text { Carrier }\end{array}$} & \multirow[b]{2}{*}{$\begin{array}{l}\text { Market } \\
\text { Share }\end{array}$} & \multicolumn{5}{|c|}{ Route Distance (Miles) } & \multirow[b]{2}{*}{ All } \\
\hline & & & $<200$ & $\begin{array}{l}200- \\
500\end{array}$ & $\begin{array}{l}500- \\
1000\end{array}$ & $\begin{array}{l}1000- \\
1500\end{array}$ & $>1500$ & \\
\hline CAN & $\mathbf{C Z}$ & $48.12 \%$ & & & & & & \\
\hline Hub carrier & & & 2.30 & 1.92 & 1.52 & 1.72 & 1.30 & 1.69 \\
\hline Non-hub carrier & & & - & 2.34 & 1.78 & 1.48 & 0.60 & 1.81 \\
\hline Average & & & 2.30 & 2.11 & 1.67 & 1.57 & 0.83 & 1.76 \\
\hline PEK & CA & $33.61 \%$ & & & & & & \\
\hline Hub carrier & & & - & 1.99 & 1.44 & 1.72 & - & 1.62 \\
\hline Non-hub carrier & & & 2.52 & 2.08 & 1.66 & 1.47 & 0.75 & 1.66 \\
\hline Average & & & 2.52 & 2.04 & 1.58 & 1.56 & 0.75 & 1.64 \\
\hline PVG & MU & $28.55 \%$ & & & & & & \\
\hline Hub carrier & & & - & 2.04 & 1.88 & & - & 1.95 \\
\hline Non-hub carrier & & & 5.04 & 2.39 & 1.78 & 1.30 & - & 1.87 \\
\hline Average & & & 5.04 & 2.27 & 1.80 & 1.30 & - & 1.88 \\
\hline SHA & MU & $32.29 \%$ & & & & & & \\
\hline Hub carrier & & & 2.87 & 1.84 & 1.80 & - & - & 1.85 \\
\hline Non-hub carrier & & & - & 2.01 & 1.87 & 1.63 & 0.56 & 1.82 \\
\hline Average & & & 2.87 & 1.96 & 1.85 & 1.63 & 0.56 & 1.83 \\
\hline 2002 Q3 & & & & & Distan & Miles) & & \\
\hline Premium & $\begin{array}{l}\text { Hub } \\
\text { Carrier }\end{array}$ & $\begin{array}{l}\text { Market } \\
\text { Share }\end{array}$ & $<200$ & $\begin{array}{l}200- \\
500\end{array}$ & $\begin{array}{l}500- \\
1000\end{array}$ & $\begin{array}{l}1000- \\
1500\end{array}$ & $>1500$ & All \\
\hline CAN & $\mathrm{CZ}$ & $48.12 \%$ & & & & & & \\
\hline Hub carrier & & & - & 2.85 & 2.51 & 2.57 & 2.80 & 2.57 \\
\hline Non-hub carrier & & & - & 3.94 & 2.64 & 2.55 & - & 2.65 \\
\hline Average & & & - & 2.99 & 2.54 & 2.56 & 2.80 & 2.59 \\
\hline PEK & CA & $33.61 \%$ & & & & & & \\
\hline Hub carrier & & & - & 3.49 & 2.67 & 2.66 & - & 2.77 \\
\hline Non-hub carrier & & & - & 2.56 & 2.73 & 2.47 & 2.00 & 2.66 \\
\hline Average & & & - & 3.17 & 2.69 & 2.57 & 2.00 & 2.73 \\
\hline PVG & MU & $28.55 \%$ & & & & & & \\
\hline Hub carrier & & & - & 2.80 & 2.61 & - & - & 2.75 \\
\hline Non-hub carrier & & & - & 3.49 & 2.63 & 2.08 & - & 2.64 \\
\hline Average & & & - & 2.85 & 2.63 & 2.08 & - & 2.69 \\
\hline SHA & MU & $32.29 \%$ & & & & & & \\
\hline Hub carrier & & & 4.01 & 2.91 & 2.80 & - & - & 2.89 \\
\hline Non-hub carrier & & & - & 2.89 & 2.64 & 2.10 & - & 2.64 \\
\hline Average & & & 4.01 & 2.90 & 2.70 & 2.10 & - & 2.73 \\
\hline
\end{tabular}

Note: Market share calculated by capacity. Yields are in CNY per mile.

Source: The author, compiling from Sabre ADI Database. 
Table 3-3 Comparisons of Average Fare per Mile (Yield) for Flights from Dominant Airports in $3^{\text {rd }}$ Quarter, 2012

\begin{tabular}{|c|c|c|c|c|c|c|c|c|}
\hline \multirow{2}{*}{$\begin{array}{l}2012 Q 3 \\
\text { Economy }\end{array}$} & \multirow[b]{2}{*}{$\begin{array}{l}\text { Hub } \\
\text { Carrier }\end{array}$} & \multirow[b]{2}{*}{$\begin{array}{l}\text { Market } \\
\text { Share }\end{array}$} & \multicolumn{5}{|c|}{ Route Distance (Miles) } & \multirow[b]{2}{*}{ All } \\
\hline & & & $<200$ & $\begin{array}{l}200- \\
500\end{array}$ & $\begin{array}{l}500- \\
1000\end{array}$ & $\begin{array}{l}1000- \\
1500\end{array}$ & $>1500$ & \\
\hline CAN & $\mathrm{CZ}$ & $50.82 \%$ & & & & & & \\
\hline Hub carrier & & & 2.38 & 1.81 & 1.26 & 1.06 & 0.94 & 1.37 \\
\hline Non-hub carrier & & & - & 1.65 & 1.26 & 1.06 & 0.96 & 1.30 \\
\hline Average & & & 2.38 & 1.75 & 1.26 & 1.06 & 0.95 & 1.33 \\
\hline PEK & CA & $41.90 \%$ & & & & & & \\
\hline Hub carrier & & & 2.48 & 2.19 & 1.42 & 1.06 & 1.25 & 1.48 \\
\hline Non-hub carrier & & & - & 2.02 & 1.39 & 1.05 & 1.19 & 1.40 \\
\hline Average & & & 2.48 & 2.10 & 1.40 & 1.05 & 1.21 & 1.43 \\
\hline PVG & MU & $47.21 \%$ & & & & & & \\
\hline Hub carrier & & & 3.21 & 1.99 & 1.43 & 1.04 & 0.91 & 1.45 \\
\hline Non-hub carrier & & & - & 1.58 & 1.47 & 1.04 & 0.90 & 1.35 \\
\hline Average & & & 3.21 & 1.80 & 1.45 & 1.04 & 0.90 & 1.39 \\
\hline SHA & MU & $56.64 \%$ & & & & & & \\
\hline Hub carrier & & & - & 1.72 & 1.36 & 0.98 & 0.91 & 1.41 \\
\hline Non-hub carrier & & & - & 1.67 & 1.36 & 1.03 & 0.92 & 1.40 \\
\hline Average & & & - & 1.69 & 1.36 & 1.00 & 0.92 & 1.41 \\
\hline 2012 Q3 & & & & & Distan & niles) & & \\
\hline Premium & $\begin{array}{l}\text { Hub } \\
\text { Carrier }\end{array}$ & $\begin{array}{l}\text { Market } \\
\text { Share }\end{array}$ & $<200$ & $\begin{array}{l}200- \\
500\end{array}$ & $\begin{array}{l}500- \\
1000\end{array}$ & $\begin{array}{l}1000- \\
1500\end{array}$ & $>1500$ & All \\
\hline CAN & $\mathrm{CZ}$ & $50.82 \%$ & & & & & & \\
\hline Hub carrier & & & - & 3.50 & 2.99 & 2.60 & 1.40 & 2.99 \\
\hline Non-hub carrier & & & - & 4.57 & 3.04 & 3.35 & 2.36 & 3.21 \\
\hline Average & & & - & 3.63 & 3.01 & 2.98 & 1.52 & 3.07 \\
\hline PEK & CA & $41.90 \%$ & & & & & & \\
\hline Hub carrier & & & 7.25 & 5.17 & 3.98 & 3.37 & 3.66 & 4.09 \\
\hline Non-hub carrier & & & - & 4.92 & 3.85 & 3.10 & 2.46 & 3.87 \\
\hline Average & & & 7.25 & 5.06 & 3.92 & 3.25 & 2.96 & 3.99 \\
\hline PVG & MU & $47.21 \%$ & & & & & & \\
\hline Hub carrier & & & 11.50 & 5.80 & 3.53 & 2.72 & 2.34 & 3.96 \\
\hline Non-hub carrier & & & - & 4.94 & 3.28 & 3.09 & 2.49 & 3.38 \\
\hline Average & & & 11.50 & 5.58 & 3.39 & 2.92 & 2.43 & 3.67 \\
\hline SHA & MU & $56.64 \%$ & & & & & & \\
\hline Hub carrier & & & - & 4.27 & 3.97 & 6.21 & 2.58 & 4.11 \\
\hline Non-hub carrier & & & - & 4.77 & 3.65 & 2.60 & 2.55 & 3.72 \\
\hline Average & & & - & 4.36 & 3.83 & 5.75 & 2.56 & 3.96 \\
\hline
\end{tabular}

Note: Market share calculated by capacity. Yields are in CNY per mile.

Source: The author, compiling from Sabre ADI Database. 


\subsection{Summary}

In summary, this chapter provides background information of the Chinese airline industry on which the empirical analysis will be based. After a brief review of deregulation and airline consolidation in Chinese domestic market, the development of "Big Three" (CA, MU and CZ) carriers and their hub airports (PEK, SHA/PVG and CAN) were examined.

In the past decade, the market share of the Big Three at their primary hubs has increased from around $30 \%$ in 2002 to more than $50 \%$ in 2012. The HHI was relatively stable and was highly concentrated during the sample period. Moreover, it is observed that hub carriers' premium passenger ratio was above average at hub airports. A comparison of yields for flights from major airports between hub carriers and non-hub carriers provided preliminary evidence of pricing power of hub airlines due to the increased airport market share. The results provide initial support for the existence of hub premiums. However, when the market was segmented by distance, mixed results were emerged suggesting it is essential to take time period effects and distance into account in the econometric exercises.

In the next chapter, the difference of pricing power will be formally tested by performing a set of fixed-effects panel data models which allow us to identify the effects of airport dominance on economy class fares and premium class fares, respectively using variation in airport market share over time within a given route. 


\section{Chapter 4 Methodology}

This chapter describes the methodology used for the thesis. Instead of using cross sectional analysis commonly adopted by previous studies in this area, the fixed-effect models are employed to estimate our panel data regression models. Moreover, instrumental variables (IV) approach is used to deal with the endogeneity problem. This chapter is structured as follows. Section 4.1 reviews key methods in panel data analysis. Section 4.2 specifies the econometric model used in the empirical study and discusses the expected relationship between each of the explanatory variables and the dependent variable. Section 4.3 reports the data sources of this study and explains issues when constructing the database. Section 4.4 discusses the issues of endogeneity and the solutions to this problem. And Section 4.5 summarized this chapter.

\subsection{Panel Data Analysis}

\subsubsection{Panel Data Analysis versus Cross Sectional Analysis}

The types of data generally used in empirical studies are time series, cross section and panel (Gujarati and Porter, 2009). Time series data observes values of variables of single unit over a period of time, while cross sectional data focus on the values of variables collected for several sample units at the same point of time. Panel data could be treated as a hybrid of cross-sectional and time-series data (Ashley, 2012), in which a group of cross sectional units are observed over time, which means that there are two dimensions of data individual dimension and time dimension.

Panel data model - the regression model based on panel data - has become increasingly popular in empirical research due to its powerful capacity for capturing the complexity of reality - more specifically, the complexity of human 
behaviour. Comparing to conventional cross-sectional and time-series data model, there are several advantages to using panel data (see Hsiao, 2003; Gujarati and Porter, 2009 for details). First, techniques of panel data estimation are able to control for individual heterogeneity. Panel data deal with the sample units like individuals, firms, states or countries, which are heterogeneous. Time-series and cross-section studies not controlling this will lead to bias in the resulting estimates. Panel data estimation can take such heterogeneity explicitly into account by controlling for unit-invariant and time-invariant variables. Particularly, one may effectively control for all unit-specific characteristics no matter whether they are observable or not when employing panel data analysis. Second, panel data gives more informative data, more variability, less collinearity among variables by combining time series of crosssection observations. Third, by studying repeated cross-section observations, panel data are better suited to study the dynamics of adjustment. Changes will be hidden by stable cross-sectional data; hence panel data enables us to observe the effects of policy changes if the time period is long enough.

\subsubsection{Estimation Techniques for Panel Data}

A panel data regression differs from a regular time-series or cross-section regression in that it has a double subscript on its variables, i.e.

$$
y_{\mathrm{it}}=\alpha+\sum_{k=1}^{K} \beta_{k} x_{k i t}+u_{i t,} \quad i=1, \ldots, N ; t=1, \ldots, T
$$

with $i$ denoting the $i$ th individual and $t$ denoting time. $\alpha$ is a scalar whereas $\beta$ is a $K \times I$ matrix. $x_{k i t}$ denotes $k$ th explanatory variable for $i t$ th observation.

There are several options of estimating a panel data model, depending on the data characteristics and different assumptions. Each of them is briefly discussed below. 
1) Pooled Ordinary Least Squares (POLS) model

If we pooled together all observations, assuming the regression coefficients are the same for all individuals, it means that there is no distinction between individuals, firms or countries, which is known as the overall homogeneity hypothesis. Additionally, it is assumed that the explanatory variables $x_{i t}$ are strictly exogenous, which means that they are uncorrelated with the current, past and future values of the error term $u_{i t}$. In fact, the assumptions are always not grounded for many empirical studies. Then if we ignore the heterogeneity among the individuals or firms, it may result in the risk that the error term may be correlated with some of explanatory variables. As a consequence, the OLS estimation will lead to biased and inconsistent results.

There are several techniques to address these problems, taking into account the estimation of unobserved effects. The two most prominent methods are the fixed-effects (FE) estimator and the random-effects (RE) estimator (Gujarati and Porter, 2009; Hill et al., 2008; etc.).

To make the description easier to understand, two-way composite error term (see Baltagi, 2008) is used to express the disturbances in model (4-1):

$$
u_{i t}=\mu_{i}+\lambda_{t}+v_{i t} \quad i=1, \ldots, N ; t=1, \ldots, T
$$

Where $\mu_{i}$ denotes the unobservable individual specific effect which is constant over time, $\lambda_{t}$ denotes the unobservable time effect, and $v_{i t}$ is the remainder stochastic term that change over time and affect $y_{i t}$. Before proceeding to FE and RE model, it is worth pointing out that the POLS estimation is usually biased and inconsistent even we assume that the stochastic error $v_{i t}$ is uncorrelated with explanatory variables. This is because the individual effect $\mu_{i}$ is inherently correlated with $x_{i t}$, hence $u_{i t}$ and $x_{i t}$ is still correlated. 


\section{2) Fixed-effects (FE) model}

In a FE model, $\mu_{i}$ are assumed to be fixed parameters to be estimated, and the stochastic error $v_{i t}$ are independent and identically distributed random variables. The $x_{i t}$ is assumed to be uncorrelated with $v_{i t}$.

The FE estimator uses a transformation to wipe out the unobservable individual effects prior to estimation. More precisely, for each $i$, we firstly average the original equation over time, and then subtract the mean expression from original equation that obtain a time-demean form equation, finally estimate the transformed equation by OLS. After the time-demeaned transform, the unobservable effect $\mu_{i}$ has been removed; hence, the OLS estimation is no longer biased. The fixed-effect estimator is also called within estimator, because the OLS estimate in the last step uses the time variation in $\mathrm{y}$ and $\mathrm{x}$ within each cross-sectional observation.

A distinctive advantage of the FE model is that it allows for correlation between $\mu_{i}$ and $x_{i t}$ at any time period. It is an attractive approach when we focus on investigating a specific set of individuals or firms. The inference, however, is restricted to the behaviour of the given group of individuals and over the specific observed time periods. There are also some disadvantages associated with the FE model. First of all, it is not able to estimate time-invariant explanatory variables. Moreover, given the extensive use of dummy variables to control for time period and individual specific effects, FE model consumes a lot of degrees of freedom, thus may reduce the efficiency of estimation. This is particularly the case when the number of observations is small.

3) Random-effects (RE) model 
If the time-invariant individual-specific effect $\mu_{i}$ can be assumed to be independent and identically distributed random variables, then we can avoid using FE model which contains too many parameters and consumes a lot of degrees of freedom. This turns out to be the random-effects (RE) model.

There is an additional requirement for $\mathrm{RE}$ model that $\mu_{i}$ is uncorrelated with each explanatory variable in all time periods except for all the FE model assumptions. In this case, $\mu_{i}$ and $v_{i t}$ are independent and identically distributed random variables, $\mu_{i}$ and $v_{i t}$ are uncorrelated, $x_{i t}$ is uncorrelated with $\mu_{i}$ or $v_{i t}$ for all $i$ and $t$.

The RE model is an appropriate specification when randomly sampling $N$ individuals from a large population. When $N$ is large, a FE model will lead to a huge loss of degrees of freedom. Then one of the advantages of RE model over FE model is that it is more efficient, as we do not have to estimate $N$ crosssectional intercepts instead of estimating the mean value of the intercept and its variance. Another advantage of $\mathrm{RE}$ model is that the time-invariant variables can be introduced into the model and be estimated properly.

Finally, when considering which model to choose, one should first think carefully from theoretical perspective to check the applicability of the properties and assumptions of the different techniques. Although there is a conventional specification test being well known as Hausman (1978) Test, which is based on testing whether the estimation by FE and RE models are significantly different, the information it provides is limited (Hsiao,.2003). In practice, researchers always interpret the rejection of the test as the support for the use of FE model and non-rejection as RE model. However, the more reliable decision should be made based on theory. In this study, the research focuses on all route-carrier 
pairs in the market. The estimation is based on the population rather than the sample. The individual-specific effects are unlikely to be random. Thus FE model should be an appropriate model to be adopted. More advantages of using FE model will be further elaborated in the following section.

\subsection{Model}

\subsubsection{Empirical model}

Most of the previous studies in this area were based on the analysis of crosssectional data which is incapable of illustrating the evolution of airport dominance and pricing power. This study uses panel data and employs fixedeffect model to control for time-invariant, route-carrier effects and estimates the pricing effect of airport dominance using variation in the competitiveness of a given route over time. By contrast, a cross-sectional analysis estimates the effect of airport dominance on price using variation in the competitiveness across routes. This is an important difference, as pointed out in Section 4.1.1, identification of the effect of airport dominance on price using cross-sectional data is obtained only if the researcher can control for all other differences in price determinants across markets that are correlated with differences in market structure without having to explicitly measure them. Fixed-effects panel analysis procedure addresses carrier-route dummies, which allows us to capture time-invariant characteristics specific to the carrier-route observation such as distance, tourist routes, and primary routes.

A reduce-form pricing equation is developed where demand and supply characteristics of the relevant market are included as explanatory variables, taking into account of the airline and route characteristics, and measures of market structure. Selection of variables that included in the model refers to a series of previous studies (e.g. Borenstein, 1989; Evans and Kessides, 1993; Chi and Koo, 2009). 


$$
\begin{aligned}
& \text { In Fare } \text { Fit }_{i j}=\alpha_{0}+\alpha_{1} \text { Depshare }_{i j t}+\alpha_{2} \ln \text { DepHHI } \\
& +\alpha_{4} \ln \text { ArrHHI }_{j t}+\alpha_{5} \text { Routeshare }_{i j t}+\alpha_{6} \ln \text { RouteHHI }_{i j t} \\
& +\alpha_{8} \ln \text { Pop }_{j t}+\alpha_{9} \ln \text { In Freq } \text { Income }_{i j t}+\gamma_{t}+\mu_{i j}+e_{i j t}
\end{aligned}
$$

where $i$ indexes the carrier, $j$ the route, and $t$ the time period. Carrier-route fixed effects are represented as $\mu_{i j}$. I control for principal exogenous cost and demand effects through a full set of time dummies $\gamma_{t}$. The $e_{i j t}$ stands for the random error term.

One-way directional traffic data from the four hub airports to the rest of mainland China are used. The purpose of such arrangements is to create two distinctive groups of airports with all departing airports being the four hubs and arrival airports being regional airports, so that the pricing effects between the hub and regional airports can be separated.

\subsubsection{Dependent Variables}

To investigate the pricing effects of airport dominance on economy class and premium class passengers, two models are specified. Dependent variable in Model 1 is the average one way economy class fares, while dependent variable in Model 2 is the average one way premium class fares. Fares are adjusted for inflation using CPI. Data in each model are further divided into two subsamples with sub-sample (a) being the observations for hub carriers originating from their hub airports; and sub-sample (b) being other airlines.

It is expected that the tickets of economy class are mainly bought by pricesensitive passengers. Low-price strategy may be used by airlines to attract these passengers to spread the overhead costs and improve load factor. By contrast, premium class tickets mainly target business travellers who may not to be sensitive to the price but are attracted by quality of service and loyalty 
programmes. Airport dominance may have greater power over the premium passengers than economy passengers.

\subsubsection{Market Structure Variables}

Following Hofer et al. (2008), airport dominance, airport concentration, route dominance and route concentration are used to measure dominance and concentration at the airport and route level. The key variable which to be most interested in this study is airport market share, which is defined as the capacity share of focal airline $i$ on route $j$ in period $t$. Generally, the expected sign of airport market share should be positive. An airline with a dominant share at an airport will obtain competitive advantages from: 1) dominant reputation acquired by offering most of the flights to and from the city (Borenstein, 1989); 2) control of scarce airport resources such as availability of slots and gates especially at congested airports; 3) Frequent-flyer-programs (FFPs) becomes more attractive because of extensive network and more often future flights expectation. In summary, when an airline provides a large share of capacity at an airport, its attractiveness to passengers will be enhanced, hence contributing to higher fares. However, airport dominance may also lead to fare reduction (Marin, 1995). Gaining high airport market share allows an airline to exploit the economies of scale. Cost reduction may be achieved in marketing, aircraft maintenance and labour. Lower cost may provide airlines with room for potential price cut for revenue maximization. Therefore, the sign of airport market share is not predetermined.

$\mathrm{HHI}$ is a commonly used indicator to measure airport concentration. The sign for $\mathrm{HHI}$ is not clear a priori. A dominant firm may find it more convenient and easier to maintain high prices if it competes against a fringe of small firms rather than a fairly large and well-established rival. In the first scenario the HHI would 
be smaller than in the second ${ }^{4}$ and the predicted sign would be negative. However, holding market share constant, a higher $\mathrm{HHI}$ may make it more feasible for firms to collude, hence raising prices, which suggests a positive sign (Fischer and Kamerschen, 2003).

Instead of using weighted airport share or airport $\mathrm{HHI}$ of both origin and destination airports, this study distinguishes departure and arrival airports with DepShare variable representing an airline's market share at departure airports and ArrShare variable for an airline's market share at arrival airports. In the same manner, $\mathrm{HHI}$ is also separated into DepHHI and ArrHHI. In our dataset, the departure airports are the 4 major airports, while the arrival airports are the other airports in China. Therefore, the DepShare variable is of most interest in this study which will be used to investigate the airport dominance effects.

For route-related variables, I define route market share (RouteShare) as the capacity share provided by airline $i$ on route $j$ in period $t$ while route $\mathrm{HHI}$ (RouteHHI) as the sum of the squares of route share of each airline operated on route $j$ in period $t$. Controlling for route concentration, higher route market shares is expected to be associated with higher prices. The sign of route $\mathrm{HHI}$ is, however, ambiguous. On the one hand, fewer airlines on a concentrated route make it easier to collude, hence, pushing up the price. On the other hand, if a dominant airline on a route has an outstanding competitive advantage through

\footnotetext{
${ }^{4}$ For example, assuming a dominant firm accounting for $80 \%$ of the market share:
}

- Scenario 1: it competes against a fringe of small firms, like 4 companies occupying $5 \%$ of the market each. Then $\mathrm{HHI} 1=\left(0.8^{2}+4 * 0.05^{2}\right) * 10000=6500$

- Scenario 2: it competes against a fairly large and well-established rival, like a company holding $20 \%$ of market share. Then $\mathrm{HHI} 2=\left(0.8^{2}+0.2^{2}\right){ }^{*} 10000=6800$

The $\mathrm{HHI}$ in the first scenario is smaller than in the second one, but it is easier for the dominant firm to maintain a higher price in the first scenario. 
marketing and advertising, other airlines may respond with lower fares. Therefore, route $\mathrm{HHI}$ could be either positive or negative depending on different scenarios.

\subsubsection{Control Variables}

Three control variables are included into our models. The first one is frequency $\left(\right.$ Freq $\left._{i j t}\right)$ which is measured by the number of scheduled flight departures on route $j$ operated by airline $i$ in period $t$. As discussed in section 2.1, several variables of supply side could be included in the model. Following Berry et al. (1996), I choose to control for flight frequencies in the model. The reason is that depending on demand conditions, airlines may respond to increased density by increasing flight frequency rather than by increasing aircraft size. Higher frequency of flights is likely to reduce operating costs per passenger when controlling for the load factor, because high frequencies allow airlines to plan the schedule more flexibly, thus aircraft utilization will be generally greater (Doganis, 2002; Borenstein, 1989). Frequency of service may have positive or negative impact on airfares depending on its effect on demand and operating costs (Chi \& Koo, 2009). Douglas and Miller (1974) introduced the concept of "schedule delay", which has two components. The first one is "frequency delay", which represents the elapsed time between an individual traveller's preferred time and the time of a scheduled flight. The second one is called "stochastic delay", which represents the additional elapsed time when preferred flights are fully booked. Higher frequency lowers frequency delay, thus increasing the value of the product, especially for time-sensitive passengers. (Borenstein, 1989). More specifically, a higher frequency of flights may provide passengers more chances to get a ticket for their preferred schedules, as well as decreasing the waiting time for next flight when the reserved one is cancelled. If the stimulation of demand is dominant, the sign is expected to be positive, particularly for business oriented routes and premium class fares. However, if the cost reduction effect is dominant, the sign will be negative. 
The other two control variables are Population $\left(\right.$ Pop $\left._{j t}\right)$ and Income (Income $\left.e_{j t}\right)$. Both variables are conventional indicator of potential market size, thus the demand factors. Population is measured by the geometric mean of the endpoint city population of route $j$ in period $t$. Income is measured by the geometric mean of the GDP per capita of the endpoint city of route $j$ in period $t$. Income data have been adjusted for inflation by using CPI. Higher incomes and more population may affect demand thus fares by raising the propensity for air travel in a market. However, these positive demand effects on fares could be offset through cost savings associated with higher traffic densities, which are realized when higher demand leads to the use of larger aircraft, thus reducing unit operating costs (Chi \& Koo, 2009; Brueckner et al., 2013).

Flight distance is also an undisputed important variable which is related to fuel cost and labour cost. As the distance is time invariant, hence, cannot be estimated by fixed effect models, nevertheless, the effects of distance can be captured by carrier-route specific dummies. Other time invariant variables which are captured by carrier-route specific dummies include route specific characteristics such as tourist oriented routes and business dominated routes.

\subsection{Data}

The fare data are obtained from Airport Data Intelligence (ADI) developed by Sabre Airline Solutions, in which the airfare and passenger data are based on MIDT data and adjusted to account for airline direct bookings, low-cost carriers and other non-MIDT distribution channels. Compared to the DB1B database, the ADI data have much wider coverage. Frequency data are exacted from ADI which are sourced from Innovata and OAG databases. Population and GDP per capita data are obtained from various issues of China Statistical Yearbook for Cities and China Statistical Yearbook for regional economy. 
The author then construct a panel in which an observation is a flight operated by a specific airline on a specific route (group dimension), in a specific yearquarter period (time dimension). For instance, a direct route from Beijing (PEK) to Chengdu (CTU) operated by Air China (CA) in the third quarter of 2004 is considered to be an observation in the dataset. Those observations with frequency less than 24 flights per quarter which approximately equals to 2 flights per week have been eliminated. Additionally, route served by a specific carrier with total passengers (sum of economy and premium class) less than 240 per quarter are excluded in the dataset ${ }^{5}$.

\subsection{Issues of Endogeneity}

\subsubsection{Problem of endogeneity}

A critical assumption of the classical linear regression model (CLRM) is that the unobserved factors represented by the error term are not systematically related to the regressors. Or equivalently, the expected value of the error term $u_{i}$, given the values of the regressors, is zero. Symbolically,

$$
E\left(u_{i} \mid X_{i}\right)=0
$$

With this and the other assumptions (See Gujarati, 1999), the Ordinary Least Squares (OLS) estimators can be established as the best linear unbiased estimators (BLUE). But if the assumption fails, which means that the error term and one or more regressors are correlated, the OLS estimators are biased as well as inconsistent, even in large samples. This is known as the problem of endogeneity. In this situation, even if a single regressor in a multiple regression is stochastic or endogenous, OLS estimates for all the coefficients are

\footnotetext{
${ }^{5}$ These criteria are commonly used in the literature in an effort to improve data quality.
} 
inconsistent (see Gujarati, 2011, P314). Consequently, the tests of significance and hypothesis testing become questionable.

The reasons for correlation between regressors and the error term are primarily represented as measurement errors in the regressor(s), omitted variable bias and simultaneous equation (joint determination) bias. Ashely (2012) indicates that it is not possible to directly test whether or not endogeneity in the explanatory variables is a serious problem. Hence in practice, whether or not endogeneity is present is always judged from theoretical perspective.

Typically, in empirical studies, the endogeneity discussion is always related to the possibility of correlation between an explanatory variable and the model error term due to either "reverse causation" between the dependent variable and an explanatory variable or due to "joint determination", where the dependent variable and an explanatory variable are jointly determined by a set of simultaneous equations. In terms of the "revers causality" issue, which is the most relative cause of endogeneity problem in our study, the discussion below will elaborate the problem.

The inherent causal relationship in a regression model should be like that: fluctuations in the explanatory variables cause part of the observed fluctuation in the dependent variable, with the remainder of them attributed to other causal influences which are included in the error term. A "reverse causality" is defined as that if the fluctuations in an explanatory variable not only contribute to the sample fluctuations in the dependent variable, which is the reason why this variable is included in the model, but themselves are also caused by the fluctuations in the dependent variable. This issue emerge in empirical study quite often. The primary econometric tool for dealing with reverse causality and other forms of endogeneity problem is so-called instrumental variables (IV) estimation technique, which will be introduced in coming section. 


\subsubsection{Method of instrumental variables (IV)}

A valid instrument (always denoted by $\mathrm{z}$ ) is an observed variable characterized by two properties: 1) it should be correlated with at least one of the endogenous variables (instrument relevance); 2) it should be uncorrelated, at least asymptotically, with the error term (instrument exogeneity).

The first condition is testable, because the sample correlations between $\mathrm{z}$ and the explanatory variables provide consistent estimations of the population correlations. By contrast, the exogeneity assumption cannot actually be tested in practice. The reason is exactly the same as the reason why it is not possible to directly test for endogeneity: the condition involves the model errors which are unobservable, even for large samples. In practice, it is always challenging to find specification of an apparently valid instrument for the endogenous variable. Due to the use of panel data, there is a relatively easy way to find an instrument for the endogenous variable, which will be elaborated in next section.

\subsubsection{Procedures of dealing with endogeneity}

Apparently, there are concerns of potential endogeneity with a series of righthand-side variables in model (4-3). In this case, a variable is endogenous if a change in the variable affects prices, and the prices also result in a change in the variable. Obviously, market share at route level is potentially correlated with the random error term, because offering lower price attracts more passengers hence allowing the airline to achieve a higher market share, that is, the route market share and random error term will be negatively correlated, which means least-square estimates of the coefficient on route market share would underestimate its true effect on price. As the airline's market share on a route and its size of operations at the endpoints of the route are interrelated, the DepShare and ArrShare are expected to be endogenous. So are the 
airport/route $\mathrm{HHI}$ that calculated by market share. Another suspected endogenous variable is frequency, because lower fare will increase the demand of traffic, which will increase the value of frequency.

To provide an unbiased estimate of the effects on price, an instrumental variable (IV) procedure is employed. Following Chi and Koo's (2009) approach, one-quarter lags of the endogenous variables are used as instruments in the model. The variables are all expected to be closely related to their counterparts in the following period, which satisfy the instrument relevance requirement. Moreover, the instrument exogeneity requirement (identifying exclusion restriction) holds if an airline's current prices do not respond to the market structure and capacity allocation of previous quarter.

Since the use of IV estimation must be balanced against the inevitable loss of efficiency against using OLS, it is therefore very useful to have a test of whether or not OLS is inconsistent and IV is required (Baum et al., 2003). This is the Durbin-Wu-Hausman (DWH) test of the endogeneity of regressors, which involves estimating the model via both OLS and IV approaches and comparing the resulting coefficient vectors. The null hypothesis for testing is that the OLS estimator is consistent and fully efficient. A rejection should be interpreted of the necessity of using an IV approach. In this study, the DWH test is rejected; hence, the IV technique should be necessarily used.

\subsection{Summary}

This chapter reviews key methods in panel data analysis. A comparison of the estimation techniques suggests that the fixed-effect model is the most appropriate method for this study, because the estimation is based on the population rather than the sample, and the individual-specific effects which should be controlled are unlikely to be random. And then the model 
specification is thoroughly discussed along with the advantages of FE model. Following the formulation of the models, the expected relationship between each of the explanatory variables and the dependent variable was extensively discussed. Data sources and the dataset structure were also presented. Finally, the issues of endogeneity have been discussed. The method of Instrumental Variable (IV) is employed as a solution to the problems. In addition, the two-dimensional property of panel data enables the utilization of lagged variables as instruments. It is another advantage of panel-data analysis that simplifies the creation of IV which is widely considered to be a serious challenge when conducting a cross-sectional analysis. 


\section{Chapter 5 Results and Discussions}

\subsection{Summary Statistics}

Summary statistics for the variables used in the models are reported in Table 51 and Table 5-2. In the whole sample, average fare for the premium class is CNY1783 (US\$ 257) which is about 80\% higher than that in economy class (i.e. CNY1081 or US\$174). Concentration at the route level is much higher than that at the airport level. The mean $\mathrm{HHI}$ for economy and premium class at the route level is 5367 and 4915, respectively, indicating relatively high level of concentration. Even the least concentrated route has a $\mathrm{HHI}$ of 1727 . By contrast, the mean $\mathrm{HHI}$ for departure airports is 2498. While $\mathrm{HHI}$ for the four hub airports fluctuated from 1378 to 3630 during the sample period year 2002 to 2012, HHI for the arrival airports range from highly competitive market (960) to monopoly market (10000). Moreover, there are large variations in terms of frequency, population and income, which indicate that the sample data cover diversified routes and the results could be generalised to a wide range of situations. Table 5-2 reveals some different characteristics of the two subsamples. The average market share of hub carriers at the departing airports and the routes was much higher than that of non-hub carriers.

Table 5-1 Descriptive Analysis for whole sample

\begin{tabular}{|c|c|c|c|c|c|c|c|c|}
\hline \multicolumn{9}{|c|}{ Whole Sample } \\
\hline \multirow[b]{2}{*}{ Variable } & \multicolumn{4}{|c|}{ Model 1 - Economy (Observations: 21625) } & \multicolumn{4}{|c|}{ Model2- Premium (Observations: 14940) } \\
\hline & Mean & Std. Dev. & Min & Max & Mean & Std. Dev. & Min & Max \\
\hline Fare & 1081.27 & 541.89 & 104.07 & 4989.18 & 1782.60 & 936.73 & 272.56 & 7921.10 \\
\hline DepShare & 0.2251 & 0.1749 & 0.0003 & 0.5661 & 0.2581 & 0.1697 & 0.0015 & 0.5661 \\
\hline DepHHI & 0.2498 & 0.0435 & 0.1378 & 0.3630 & 0.2487 & 0.0411 & 0.1378 & 0.3630 \\
\hline ArrShare & 0.2655 & 0.2363 & 0.0017 & 1 & 0.2574 & 0.2063 & 0.0025 & 1 \\
\hline ArrHHI & 0.3009 & 0.1841 & 0.0960 & 1 & 0.2743 & 0.1467 & 0.0960 & 1 \\
\hline RouteShare & 0.4831 & 0.3322 & 0.0117 & 1 & 0.4652 & 0.2957 & 0.0117 & 1 \\
\hline RouteHHI & 0.5367 & 0.2734 & 0.1727 & 1 & 0.4915 & 0.2460 & 0.1727 & 1 \\
\hline Frequency & 178.42 & 164.38 & 24 & 1586 & 217.96 & 178.62 & 24 & 1586 \\
\hline Population & 756.89 & 325.39 & 83.53 & 2174.01 & 775.95 & 323.14 & 90.84 & 2174.01 \\
\hline Income & 40295 & 13754 & 9860 & 93333 & 41895 & 13481 & 11518 & 93253 \\
\hline
\end{tabular}


Table 5-2 Descriptive Analysis for sub-samples

\begin{tabular}{|c|c|c|c|c|c|c|c|c|}
\hline \multicolumn{9}{|c|}{ Hub carriers } \\
\hline \multirow[b]{2}{*}{ Variable } & \multicolumn{4}{|c|}{ Model 1a-Economy (Observations: 7230) } & \multicolumn{4}{|c|}{ Model 2a-Premium (Observations: 6026) } \\
\hline & Mean & Std. Dev. & Min & Max & Mean & Std. Dev. & Min & Max \\
\hline Fare & 980.84 & 497.54 & 109.22 & 4344.85 & 1723.82 & 931.05 & 272.56 & 7921.10 \\
\hline DepShare & 0.4395 & 0.0713 & 0.1900 & 0.5661 & 0.4348 & 0.0698 & 0.1900 & 0.5661 \\
\hline DepHHI & 0.2572 & 0.0437 & 0.1378 & 0.3630 & 0.2539 & 0.0424 & 0.1378 & 0.3630 \\
\hline ArrShare & 0.2681 & 0.2250 & 0.0050 & 1 & 0.2416 & 0.1930 & 0.0050 & 1 \\
\hline ArrHHI & 0.3186 & 0.1887 & 0.0960 & 1 & 0.2876 & 0.1521 & 0.0960 & 1 \\
\hline RouteShare & 0.6355 & 0.2937 & 0.0439 & 1 & 0.5935 & 0.2783 & 0.0439 & 1 \\
\hline RouteHHI & 0.6133 & 0.2885 & 0.1727 & 1 & 0.5622 & 0.2717 & 0.1727 & 1 \\
\hline Frequency & 226.24 & 206.28 & 24 & 1586 & 255.56 & 212.26 & 24 & 1586 \\
\hline Population & 728.76 & 303.85 & 83.53 & 2174.01 & 750.97 & 310.09 & 90.84 & 2174.01 \\
\hline Income & 39035 & 13508 & 11315 & 93253 & 40616 & 13432 & 11518 & 93253 \\
\hline \multicolumn{9}{|c|}{ Non-hub carriers } \\
\hline & \multicolumn{4}{|c|}{ Model 1b-Economy (Observations: 14395) } & \multicolumn{4}{|c|}{ Model 2b-Premium (Observations: 8914 ) } \\
\hline Variable & Mean & Std. Dev. & Min & Max & Mean & Std. Dev. & Min & Max \\
\hline Fare & 1131.71 & 556.07 & 104.07 & 4989.18 & 1822.34 & 938.53 & 272.56 & 6829.68 \\
\hline DepShare & 0.1174 & 0.0933 & 0.0003 & 0.5606 & 0.1386 & 0.0979 & 0.0015 & 0.5606 \\
\hline DepHHI & 0.2460 & 0.0429 & 0.1378 & 0.3630 & 0.2452 & 0.0398 & 0.1378 & 0.3630 \\
\hline ArrShare & 0.2641 & 0.2418 & 0.0017 & 1 & 0.2680 & 0.2142 & 0.0025 & 1 \\
\hline ArrHHI & 0.2920 & 0.1811 & 0.0960 & 1 & 0.2652 & 0.1422 & 0.0960 & 1 \\
\hline RouteShare & 0.4066 & 0.3240 & 0.0117 & 1 & 0.3785 & 0.2749 & 0.0117 & 1 \\
\hline RouteHHI & 0.4982 & 0.2570 & 0.1727 & 1 & 0.4436 & 0.2142 & 0.1727 & 1 \\
\hline Frequency & 154.41 & 132.28 & 24 & 1009 & 192.54 & 146.35 & 24 & 1009 \\
\hline Population & 771.02 & 334.81 & 83.53 & 2174.01 & 792.83 & 330.62 & 90.84 & 2174.01 \\
\hline Income & 40928 & 13833 & 9860 & 93333 & 42760 & 13445 & 13094 & 89010 \\
\hline
\end{tabular}

There does not appear to be excessive multicollinearity between independent variables except the route market share and route $\mathrm{HHI}$, which is correlated at $0.8^{6}$. Following the recommendation of Aiken and West (1991), the meancentring values of route market share are used which has reduced the correlation between route share and route $\mathrm{HHI}$ to 0.01 . It should be noted that such rescaling has no effect on the coefficients of linear regression.

\footnotetext{
${ }^{6}$ Correlation matrices for the models are presented in Appendix B.
} 


\subsection{Results of the Regression Models}

Table 5-3 reports the estimation results for the models. Carrier-route-specific dummies and time dummies are omitted to conserve space. First two columns in Table 5-3 report the results for Model 1 (economy - all) and Model 2 (premium - all). The first thing to notice is that airport dominance is more important than route dominance in determining an airline's prices at the route level. The coefficients of departure airport market share are highly statistically significant at the $1 \%$ level for both economy and premium markets. Although the coefficient of route share for the premium market is significant, its magnitude is relatively small compared to that of airport market share $(0.1609$ vs. 0.5387). Furthermore, the coefficient of route market share for economy class market is statistically insignificant. These results are consistent with the findings of Evans and Kessides (1993) and Hofer et al. (2008) in their study of the US domestic market where airport dominance plays a more important role than route dominance in determining airfares at the route level. However, their studies have not separated the market into premium and economy. 
Table 5-3 Estimation results

\begin{tabular}{|c|c|c|c|c|c|c|}
\hline & Model 1 & Model 2 & Model 1a & Model 1b & Model 2a & Model 2b \\
\hline \multirow[b]{2}{*}{ Variable } & Economy & Premium & \multicolumn{2}{|c|}{ Economy } & \multicolumn{2}{|c|}{ Premium } \\
\hline & All & All & $\begin{array}{l}\text { Hub } \\
\text { carriers }\end{array}$ & $\begin{array}{c}\text { Non-hub } \\
\text { carriers }\end{array}$ & $\begin{array}{l}\text { Hub } \\
\text { carriers }\end{array}$ & $\begin{array}{l}\text { Non-hub } \\
\text { carriers }\end{array}$ \\
\hline DepShare & $\begin{array}{c}-0.2292^{* * *} \\
(0.0598)\end{array}$ & $\begin{array}{c}0.5387^{* * *} \\
(0.0790)\end{array}$ & $\begin{array}{l}-0.0357 \\
(0.1278)\end{array}$ & $\begin{array}{l}-0.2067^{* * *} \\
(0.0709)\end{array}$ & $\begin{array}{c}0.9220^{* * *} \\
(0.1552)\end{array}$ & $\begin{array}{l}0.3897^{* * *} \\
(0.0995)\end{array}$ \\
\hline InDepHHI & $\begin{array}{c}0.3781^{* * *} \\
(0.0399)\end{array}$ & $\begin{array}{c}0.2189 * * * \\
(0.0544)\end{array}$ & $\begin{array}{c}0.6007^{* * *} \\
(0.0686)\end{array}$ & $\begin{array}{l}0.1903^{* * *} \\
(0.0490)\end{array}$ & $\begin{array}{c}0.3413^{* * *} \\
(0.0851)\end{array}$ & $\begin{array}{l}0.0758 \\
(0.0711)\end{array}$ \\
\hline ArrShare & $\begin{array}{l}-0.0228 \\
(0.0367)\end{array}$ & $\begin{array}{c}-0.1366^{* *} \\
(0.0570)\end{array}$ & $\begin{array}{c}0.1352 * * \\
(0.0590)\end{array}$ & $\begin{array}{l}-0.1096 * * \\
(0.0475)\end{array}$ & $\begin{array}{c}0.0021 \\
(0.0846)\end{array}$ & $\begin{array}{l}-0.1947 * * \\
(0.0797)\end{array}$ \\
\hline InArrHHI & $\begin{array}{c}-0.0538^{* * *} \\
(0.0170)\end{array}$ & $\begin{array}{l}-0.0018 \\
(0.0241)\end{array}$ & $\begin{array}{c}-0.1165^{* * *} \\
(0.0261)\end{array}$ & $\begin{array}{l}0.0076 \\
(0.0223)\end{array}$ & $\begin{array}{l}-0.0049 \\
(0.0329)\end{array}$ & $\begin{array}{l}-0.0073 \\
(0.0359)\end{array}$ \\
\hline RouteShare & $\begin{array}{l}-0.0359 \\
(0.0446)\end{array}$ & $\begin{array}{c}0.1609 * * * \\
(0.0603)\end{array}$ & $\begin{array}{c}0.0493 \\
(0.0748)\end{array}$ & $\begin{array}{l}-0.045 \\
(0.0567)\end{array}$ & $\begin{array}{c}0.1506 \\
(0.0929)\end{array}$ & $\begin{array}{l}0.2350^{* * *} \\
(0.0829)\end{array}$ \\
\hline InRouteHHI & $\begin{array}{c}0.0855^{* * *} \\
(0.0151)\end{array}$ & $\begin{array}{c}0.0293 \\
(0.0205)\end{array}$ & $\begin{array}{c}0.1359 * * * \\
(0.0253)\end{array}$ & $\begin{array}{l}0.0482^{* *} \\
(0.0190)\end{array}$ & $\begin{array}{c}0.0122 \\
(0.0313)\end{array}$ & $\begin{array}{l}0.0524^{*} \\
(0.0279)\end{array}$ \\
\hline InFreq & $\begin{array}{c}0.0024 \\
(0.0107)\end{array}$ & $\begin{array}{c}0.0095 \\
(0.0149)\end{array}$ & $\begin{array}{l}-0.0241 \\
(0.0166)\end{array}$ & $\begin{array}{l}0.0237^{*} \\
(0.0143)\end{array}$ & $\begin{array}{c}0.0031 \\
(0.0212)\end{array}$ & $\begin{array}{l}0.0084 \\
(0.0217)\end{array}$ \\
\hline InPop & $\begin{array}{c}0.0309 * * * \\
(0.0117)\end{array}$ & $\begin{array}{c}-0.0323^{* *} \\
(0.0161)\end{array}$ & $\begin{array}{c}0.0294 \\
(0.0221)\end{array}$ & $\begin{array}{l}0.0321^{* *} \\
(0.0135)\end{array}$ & $\begin{array}{l}-0.0152 \\
(0.0269)\end{array}$ & $\begin{array}{c}-0.0379 * \\
(0.0199)\end{array}$ \\
\hline Inincome & $\begin{array}{c}-0.0688^{* *} \\
(0.0286)\end{array}$ & $\begin{array}{c}-0.1103^{* * *} \\
(0.0401)\end{array}$ & $\begin{array}{c}-0.0058 \\
(0.0501)\end{array}$ & $\begin{array}{l}-0.0632^{*} \\
(0.0345)\end{array}$ & $\begin{array}{l}0.1050 * \\
(0.0630)\end{array}$ & $\begin{array}{l}-0.2293^{* * *} \\
(0.0521)\end{array}$ \\
\hline No. of Obs. & 19735 & 14157 & 6741 & 12994 & 5732 & 8425 \\
\hline Within $R^{2}$ & 0.3646 & 0.1246 & 0.3642 & 0.3911 & 0.137 & 0.1359 \\
\hline
\end{tabular}

Notes: 1$)^{*} \mathrm{p}<0.10 ; * * \mathrm{p}<0.05 ; * * * \mathrm{p}<0.01$

2) Standard errors are reported in parentheses.

3) Some of observations are not used because of singleton group.

It is interesting to find the coefficient of DepShare has a positive sign for premium market but negative sign for economy market. More specifically, the results indicate that everything else being equal, when an airline's market share at the four major airports increases by $1 \%$, the airline's premium fare would go up by $0.54 \%$ but its economy fare would go down by $0.2 \%$. The contrasting results between the premium and economy markets are a bit puzzling. To further investigate what caused the differences, the whole dataset has been divided into two sub-samples based on whether the operating airline is a hub carrier or not. 
The results of Model 2a (premium - hub carriers) and Model 2b (premium non-hub carriers) reveal that, in the premium market, if a hub carrier increases its market share by $1 \%$, on average, it is able to charge $0.92 \%$ higher ticket prices on the route. Non-hub carriers are also able to raise their prices by $0.39 \%$. In other words, hub carriers have much greater ability to translate airport dominance into pricing power than non-hub carriers.

Model 1a (economy - hub carriers) and Model 1b (economy - non-hub carriers) tell a different story. The coefficient of DepShare is insignificant, indicating increasing market share at the hub does not allow a hub carrier charge a price mark-up to the economy class passengers. However, DepShare in Model $1 \mathrm{~b}$ is negative and statistically significant at $1 \%$ level, implying that $1 \%$ increase of market share at a major airport reduces a non-hub carrier's economy class fare by $0.21 \%$.

It is important to understand the relationship between airport market share and airline pricing. On the one hand, higher market share may lead to increased market power for a hub carrier by controlling scarce airport resources to raise entry barrier for other carriers and making its FFPs more attractive, hence increasing its ability to charge higher price. On the other hand, higher airport market share help an airline achieve the economies of scale, thus reducing the airline's operating costs, hence providing the room for price reduction. Consequently, in the premium market, since most passengers are not sensitive to the price, hub carriers may take advantage of their market dominance to charge price mark-ups. The high fares charged by hub carriers may allow nonhub carriers to increase prices but at a slightly lower level. While in the economy market, most passengers are likely to be sensitive to the price, hub carriers may choose to maintain their price level while the fringe competitors 
may have to charge lower fares to attract passengers in order to gain a foothold at those highly concentrated major airports (Brueckner et al., 1992).

Having discussed the effects of hub airport on airline pricing, does dominating a regional airport make a difference? Our estimation results reveal that regional airports do not play an important role in determining the price. The coefficients of regional airport share (ArrShare) for non-hub carriers in both economy and premium markets are negative and significant. The results show that on a route linking a major hub and a regional airport, non-hub carriers do not possess any market power at the regional airport for either economy or premium market. For hub carriers, the coefficient of ArrShare is positive and significant at $5 \%$ level for economy market but it is insignificant for premium market. As presented in Table 5-2, hub carriers, on average, had a market share of $43 \%$ at the hub airport, much higher than that of non-hub carriers' market share, which stood at $12-14 \%$. However, there is almost no difference between hub carriers and nonhub carriers in their average market share at the regional airport (i.e. the other endpoint of the route) - all are around $26 \%$. These results indicate that in such hub - regional route market, only when a major airport is dominated by the hub carrier, increasing market share at regional airports enables an airline to raise up the price. Such results indicate that dominating a major airport is far more important than dominating a regional airport in terms of the impact on airline's pricing power.

Similar conclusions are drawn from the results of airport concentration variables. The effects of departure airport $\mathrm{HHI}(\mathrm{DepHHI})$ on airfares are all positive. All the coefficients, except for Model 2b (non-hub carriers in the premium market) of $\mathrm{DepHHI}$ are statistically significant at $1 \%$ level. The results indicate that the departure airport concentration has positive effects on airfares, implying that airlines at hub airports may tend to collude with each other to raise the prices; the effects on prices are stronger for hub-carriers than non-hub carriers. By contrast, the coefficient for $\mathrm{ArrHH}$ is only significant in Model 1a, but the 
magnitude is relatively small, indicating that the arrival airport $\mathrm{HHI}$ has little effect on prices at the route level. Given the fact that $\mathrm{HHI}$ is generally higher at regional airports than at hub airports (see Table 5-3 for details), apparently, airlines are not able to take advantages of concentration at regional airports to raise up price at route level. The results further confirm our previous findings that airport dominance at hub airports is crucial for an airline to exercise pricing power.

Finally, it is worth reporting that income and population variables are significant in most model specifications. The sign of the variables is positive in some models but negative in others. As what I discussed in Chapter 4, on the one hand, higher incomes and more population may have positive effects on demand and fares by raising the propensity for air travel in a market. On the other hand, higher demand leads to the use of larger aircraft, thus reducing unit operating costs, hence giving airlines ability to reduce fares. Furthermore, higher income and dense population may attract more airlines entering the market, thus increasing the level of competition which may put downward pressure on airfares.

\subsection{Interpretation of fixed effects time dummies}

During the period of our sample, Chinese domestic airline industry has experienced dramatic changes in competition, demand and cost. The estimates of quarterly dummies from 2002 to 2012 are plotted in Figure 5-1 with the first quarter of 2002 as the benchmark.

The first thing to notice is that hub and non-hub carriers followed the same pattern in economy and premium class markets. In general, prices charged by non-hub carriers increased at higher rates over time. It seems rational that in the regulated era, competition was restricted, and prices of smaller airlines 
other than Big Three were intentionally suppressed, hence larger adjustments were made. In addition, it is observed that external shocks were well captured by time effects using panel data models. Both economy and premium classes experienced a dramatic reduction in airfares in 2003 due to the spread of SARS epidemic with premium fares declining at the much faster rates than economy fares. Fares also went down in the first quarter of 2008 due to global financial crisis but quickly recovered in the second quarter.

Figure 5-1 Fixed effect time dummies

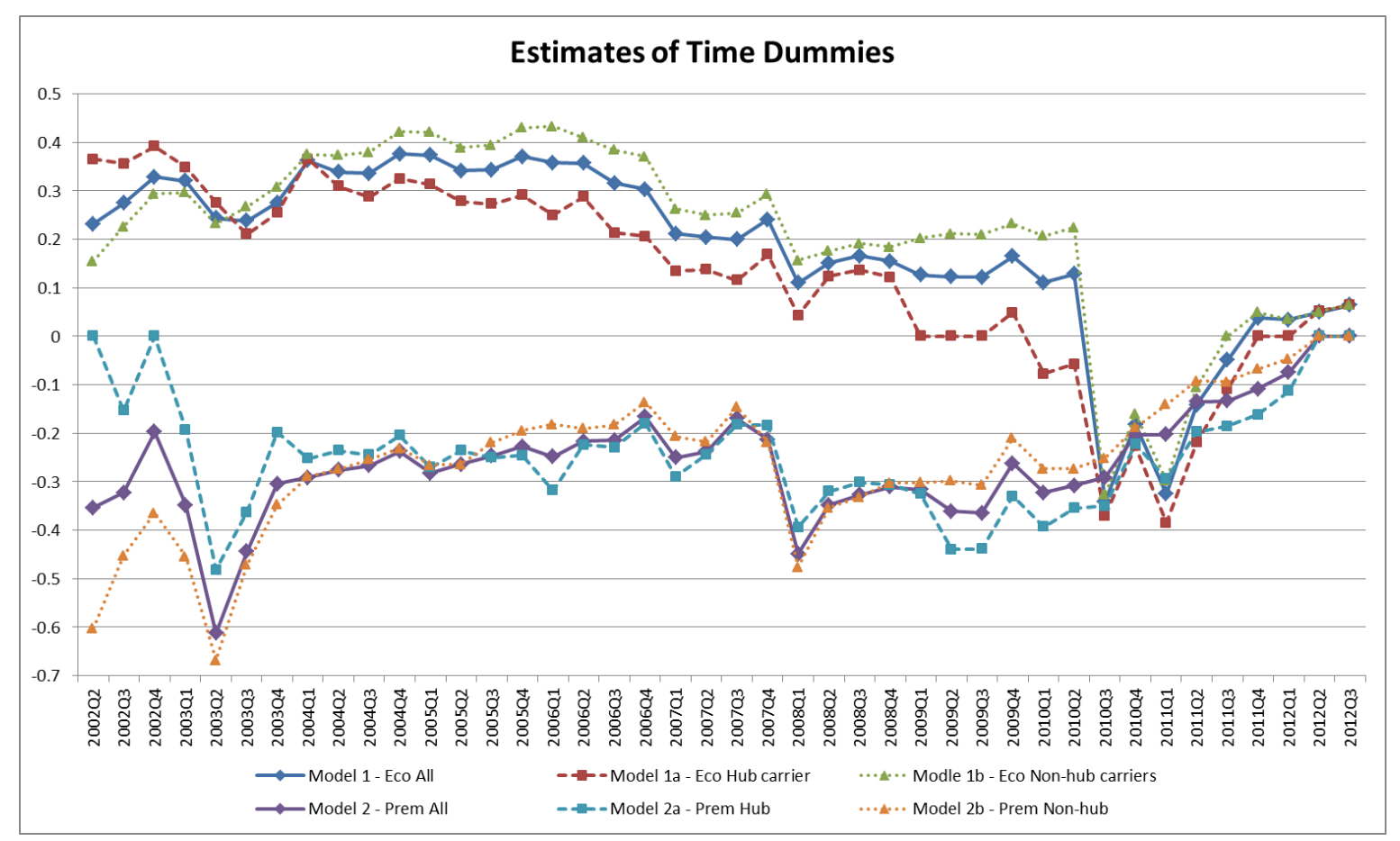

Source: The author

In the economy class market, during the period 2002 to 2005, fares were slightly higher than the benchmark quarter, i.e. the first quarter of 2002, reflecting airlines' ability to increase fares following 2002 airline consolidation after all the variables have been controlled for. The opening up of the domestic market in 2005 and the gradually deregulation of airline pricing saw a steady decline of the fares from 2005 to 2010. 
In the premium market, fares were relatively stable from 2002 to 2010 except for the two one-off events: 2003 SARS epidemic and 2008 financial crisis. The stability of the premium fares is probably because the fares were partially regulated. Following the complete deregulation of the premium fares in 2010, airlines seemed able to increase fares, perhaps a reflection of increased market power following further wave of consolidation of the market. This effect was also reflected in the economy class market. Interestingly, since the third quarter of 2010, the evolution of both economy and premium class fares have converged, providing strong evidence that the prices were determined by the market

\subsection{Summary}

This chapter started with a discussion of summary statistics. It is worth highlighting that this study is based on a very large database with more than 35,000 observations in the whole sample. There are large variations for almost all variables indicating that the sample data cover a variety of different routes and the results could be generalised to a wide range of situations. In the regression analysis, a key finding is that airport dominance is more important than route dominance in determining an airline's prices at the route level. Furthermore, hub carriers have much greater ability to translate airport dominance into pricing power than non-hub carriers. Further analysis was conducted to understand the time effects on airfares. Some interesting results were observed when China was moving from a tightly controlled regime to a deregulated market. 



\section{Chapter 6 Summary and Conclusions}

This chapter concludes the whole thesis. A summary of literature review is presented first, followed by discussions of key findings. After that, the originality of the thesis and its contributions to the body of knowledge are highlighted. Finally, the limitations of this research are acknowledged and some thoughts on further research are proposed.

\subsection{Summary of Literature Review}

Extensive literature review on airport dominance and pricing power was conducted in Chapter 2. An examination of the determinants of airline pricing provided a solid foundation for the following empirical analysis. After that, literature on airline market power and hub premiums was reviewed. Initially, the debates were focused on whether or not there existed market power in the airline industry. When it came to an agreement that the market power generally exists, studies were evolved from simple measurement of aggregated price mark-ups at airport level without controlling for many other important factors, to research investigating the effects of market structure on airfares with a more comprehensive approach of how various market forces interact in determining airline pricing.

The literature review on hub premiums was mostly based on empirical studies in the context of the US domestic market, however, as Tretheway and Kincaid (2005) pointed out that results obtained from the US studies cannot be simply extended to other markets given varied market structure characteristics, different progress of deregulation, and diverse policy environments of the airline markets throughout the world. Hence, several empirical studies for European market were reviewed. The results indicated that when Europe moved from partial to full deregulation, there were different effects of airport dominance on 
airline pricing. Nevertheless, unavailability of reliable fare data casts doubts on the validity of the results.

Given the absence of reliable research outside of the US market, a study into the changing Chinese domestic market was particularly interesting when it is evolving from a tightly deregulated regime to a liberal market. Chapter 3 , thus, reviewed the deregulation and airline consolidation in China. After that, there were discussions of the development of major hub airports with particular focus on airport dominance and airport concentration. The average yields of the Big Three at their primary airports were scrutinised. The analysis provided initial support for the existence of hub premiums

\subsection{Summary of Key Findings}

This thesis developed fixed-effect panel data models to assess the impact of airport dominance on airline pricing power in the Chinese domestic market. A number of interesting findings were produced in this research. First, it has been found that airport dominance is the most important source of pricing power in the gradually deregulated Chinese domestic market. This result is consistent with the findings of Evans and Kessides (1993) and Hofer et al (2008) in their study of the US domestic market where airport dominance plays a more important role than route dominance in determining airfares at the route level.

Second, hub carriers have much greater ability to translate airport dominance into pricing power than non-hub carriers in the premium market. This study has found that if a hub carrier increases its market share by $1 \%$, on average, it is able to raise up the prices by $0.92 \%$ at the route level. However, hub carriers are not able to translate its airport dominance to pricing power in the economy market, whereas non-hub carriers even have to reduce its prices as its market share at major airports increases. 
Third, this research has also found that dominating a hub airport is far more importance than dominating a regional airport for an airline to exercise pricing power at the route level. Only when a major airport is dominated by the hub carrier, increasing market share at the regional airport enables an airline to raise up the price on the major - regional airport route.

\subsection{Originality and Contributions of the Research}

This study has provided valuable insights into airport dominance and airline pricing power in the Chinese domestic market and made original contribution to the literature in a number of areas. First, this study contributes to research methodology by using fixed-effects panel data model to control for timeinvariant, route-carrier effects. By contrast, most of the previous studies were based on the analysis of cross-sectional data which is incapable of illustrating the effects of airport dominance and airline pricing power over time. Furthermore, fixed-effects panel data analysis uses carrier-route dummies, allowing us to capture time-invariant characteristics specific to the carrier-route observation such as distance, tourist routes and primary routes.

Second, this study makes important theoretical contribution to aviation literature. In this research, markets are segmented into business class and economy class so that the effects of airport dominance on airline pricing power are examined in a meaningful manner. The data are obtained from highly reliable sources including Sabre ADI and OAG which have added additional value to this research. Furthermore, it provides a comprehensive analysis of sources of hub premiums making explicit distinction between hub and non-hub airports.

Finally, this research uses China as a case study and has provided much needed insights into this fast growing market when it is transforming from a tightly controlled regime to a deregulated market. The findings of this research 
have important policy implications. It suggests that in the economy market, the cost effect of airport dominance prevails over its market power effect, which may be a good sign for policy makers. Since premium passengers represent a greater proportion of total passengers for hub carriers than for non-hub carriers, higher prices charged to premium passengers may be much more related to better quality of service, such as better network or higher frequency, provided by hub carriers other than market power. It seems that major airlines in China have not abused their market power at their hub airports. Having said that, regulators must remain vigilant on this issue and periodically review the market power of dominant airlines. As for practitioners, they can also benefit from this study to understand sources of price premiums and come up with effective strategies to improve their competitiveness.

\subsection{Limitations and Future Research}

Despite significant contribution made by this research, there are still a few limitations due to time and data constraints. First, the quality effects of airport dominance have not been quantified. This can be an interesting topic for further research. Moreover, given the fact that the hubs of the Big Three are at the different stage of development, it would be interesting to investigate whether there is any difference in the effect of airport dominance on airline pricing for each of the four hub airports. However, it is not able to separate the effect of individual hub airports due to data feature and methodological constraints. In the dataset, data for the explanatory variables, particularly, DepShare and $\mathrm{HHI}$ do not vary much over time for the same hub airport. This resulted in the failure to estimate the coefficients for the relevant variables in the fixed-effects models. An innovative approach should be developed in the future to address this issue. 


\section{REFERENCES}

Abramowitz, A. D., \& Brown, S. M. (1993). Market share and price determination in the contemporary airline industry. Review of Industrial Organization, 8(4), 419-433.

Abunassar, W., \& Koford, K. (1994). A Re-estimation of the Air Transport Association Study of Airline Fares \& Study of Airline Fares and Concentration. Logistics and Transportation Review, 30(4), 363-378.

Aiken, L. S., \& West, S. G. (1991). Multiple regression: Testing and interpreting interactions. Sage Publications.

Ashley, R. A. (2012). Fundamentals of applied econometrics, Hoboken, NJ: Wiley, 2012; $1^{\text {st }}$ ed.

Bailey, E., \& Panzar, J. (1981). The contestability of airline markets during the transition to deregulation. Law and Contemporary Problems, 44(1), 125145.

Bailey, E., \& Baumol, W. (1984). Deregulation and the theory of contestable markets. Yale Journal on Regulation, 1, 111-137.

Baltagi, B. H. (2008). Econometric analysis of panel data, Hoboken, NJ: Wiley, $2008,4^{\text {th }}$ ed.

Baum, C. F., Schaffer, M. E., \& Stillman, S. (2003). Instrumental variables and GMM: Estimation and testing. Stata Journal, 3(1), 1-31.

Baumol, W. (1982). Contestable Markets: An Uprising in the Theory of Industry Structure. The American Economic Review, 72(1), 1-15.

Belobaba, P., Odoni, A. R. and Barnhart, C. (2009), The global airline industry, Chichester, West Sussex, U.K. : Wiley, 2009.

Berry, S. (1990). Airport presence as product differentiation, American Economic Review, 80(2), 394-399

Berry, S., Carnall, M., \& Spiller, P. T. (1996). Airline hubs: costs, markups and the implication off customer heterogeneity. NBER Working Paper No. 5561

Bilotkach, V. (2007). Asymmetric Regulation and Airport Dominance in International Aviation: Evidence from the London-New York Market. Southern Economic Journal, 74(2), 505-523.

Borenstein, S. (1989). Hubs and High Fares: Dominance and Market Power in the U.S. Airline Industry. The RAND Journal of Economics, 20(3), 344-365. 
Borenstein, S. (1990). Airline mergers, airport dominance, and market power. The American Economic Review, 80(2), 400-404.

Borenstein, S. (2011) What Happened to Airline Market Power? working paper.

Bresnahan, T. F. (1989). Empirical studies of industries with market power. In R. Schmalensee \& R. D. Willig (Eds), Handbook of industrial organization Volume II. Amsterdam: Elsevier Science Publisher.

Brueckner, J. (2003). International airfares in the age of alliances: The effects of codesharing and antitrust immunity. Review of Economics and Statistics, $85,105-118$

Brueckner, J., Dyer, N., \& Spiller, P. (1992). Fare determination in airline huband-spoke networks. Rand Journal of Economics, 23(3), 309-333.

Brueckner, J., Lee, D., \& Singer, E. (2013). Airline competition and domestic US airfares: A comprehensive reappraisal. Economics of Transportation, 2, $1-17$.

Brueckner, J., \& Whalen, T. (2000). The price effects of international airline alliances. Journal of Law and Economics, 43, 503-545.

Button, K. J., \& Stough, R. R. (Eds.). (2000). Air transport networks: theory and policy implications. Edward Elgar Publishing.

Chang, Y. C. \& Williams, G., (2001). Changing the rules - amending the nationality clauses in air services agreements. Journal of Air Transport Management, 7, 207-216.

Chi, J., \& Koo, W. W. (2009). Carriers' pricing behaviors in the United States airline industry. Transportation Research Part E: Logistics and Transportation Review, 45(5), 710-724.

Doganis, R. (2002). Flying off course: The economics of international airlines, Psychology Press.

Douglas, G. W. \& Miller, J. C. (1974) Economic Regulation of Domestic Air Transport: Theory and Practice, Washington: Brookings Institution, 1974.

Dresner, M. E., \& Windle, R. J. (1992). Airport dominance and yields in the U.S. airline industry. Logistics and transportation review, 28(4), 319-339.

Evans, W., \& Kessides, I. (1993). Localized market power in the US airline industry. Review of Economics and Statistics, 75(1), 66-75 
Evans, W., Froeb, L., \& Werden, G. (1993). Endogeneity in the Concentration-Price Relationship: Causes, Consequences, and Cures. The Journal of Industrial Economics, 41(4), 431-438.

Fischer, T., \& Kamerschen, D. R. (2003). Measuring competition in the US airline industry using the Rosse-Panzar test and cross-sectional regression analyses. Journal of Applied Economics, 6(1), 73-93.

Flight international (2012), IN FOCUS: Chinese airports go global, Available from:http://www.flightglobal.com/news/articles/in-focus-chinese-airports-goglobal-378642/ (accessed on $7^{\text {th }}$ Oct 2013)

Fu, X., Homsombat, W., \& Oum, T. H. (2011). Airport-airline vertical relationships, their effects and regulatory policy implications. Journal of Air Transport Management, 17(6), 347-353.

Fu, X., Zhang, A., \& Lei, Z. (2012). Will China's airline industry survive the entry of high-speed rail? Research in Transportation Economics, 35(1), 13-25.

Giaume, S., \& Guillou, S. (2004). Price discrimination and concentration in European airline markets. Journal of Air Transport Management, 10(5), 305-310.

Gillen, D. and Lall, A., (2004). Competitive advantage of low-cost carriers: some implications for airports. Journal of Air Transport Management, 10(1), 4150 .

Graham, D., Kaplan, D., \& Sibley, D. (1983). Efficiency and competition in the airline industry. The Bell Journal of Economics, 14(1), 118-138.

Gujarati, D. N. (1999). Essentials of econometrics, Boston: McGraw-Hill, 1999; $2^{\text {nd }}$ ed.

Gujarati, D. N. \& Porter, D. C. (2009). Basic econometrics (International Edition), New York: McGraw-Hill, 2009; 5th ed.

Hill, R. C., Griffiths, W. E. and Lim, G. C. (2008). Principles of econometrics, Hoboken, NJ: Wiley, 2008; $3^{\text {rd }}$ ed.

Hofer, C., Dresner, M.\& Windle, R. (2004). Hub Premium in an Era of Low-Cost Carriers and Financial Distress, Address at the 2004 Air Transport Research Society World Conference in Istanbul, Turkey

Hofer, C., Windle, R. \& Dresner, M. (2008). Price premiums and low cost carrier competition. Transportation Research Part E: Logistics and Transportation Review, 44(5), 864-882. 
Hsiao, C. (2003). Analysis of panel data, Cambridge: Cambridge University Press, 2003; $2^{\text {nd }}$ ed.

Hurdle, G. J., Johnson, R. L., Joskow, A. S., Werden, G. J., \& Williams, M. A. (1989). Concentration, potential entry, and performance in the airline industry. The Journal of Industrial Economics, 38(2), 119-139.

Kahn, A. E. (1993). The competitive consequences of hub dominance: A case study. Review of Industrial Organization, 8(4), 381-405.

Kim, E. H., \& Singal, V. (1993). Mergers and market power: Evidence from the airline industry. American Economic Review, 83, 549-569.

Leahy, A. S. (1994). Concentration in the US airline industry. International Journal of Transport Economics, 21, 209-215.

Lee, D. (2003). Concentration and price trends in the US domestic airline industry: 1990-2000. Journal of Air Transport Management, 9(2), 91-101.

Lee, D., \& Luengo-Prado, M. (2005). The Impact of Passenger Mix on Reported" Hub Premiums" in the US Airline Industry. Southern Economic Journal, 72(2), 372-394.

Lei, Z., \& O'Connell, J. F. (2011). The evolving landscape of Chinese aviation policies and impact of a deregulating environment on Chinese carriers. Journal of Transport Geography, 19(4), 829-839.

Levine, M. E. (1987). Airline Competition in Deregulated Markets: Theory, Firm Strategy and Public Policy. Yale Journal on Regulation, 4(Spring), 393-494.

Lijesen, M. G., Rietveld, P., \& Nijkamp, P. (2001). Hub premiums in European civil aviation. Transport Policy, 8(3), 193-199.

Marin, P. L. (1995). Competition in European aviation: Pricing policy and market structure. The Journal of Industrial Economics, 43(2), 141-159.

Morrison, S., \& Winston, C. M. (1986). The economic effects of airline deregulation, Washington, D.C.: Brookings Institution Press

Morrison, S. A., \& Winston, C. (1987). Empirical implications and tests of the contestability hypothesis. Journal of Law and Economics, 30(1), 53-66.

Morrison, S., \& Winston, C. M. (1995). The evolution of the airline industry,. Washington, D.C.: Brookings Institution Press.

Morrison, S. A. (2001). Actual, Adjacent, and Potential Competition - Estimating the Full Effect of Southwest Airlines. Journal of Transport Economics and Policy, 35(2), 239-256. 
Narodick, K. G. (1972), Determinants of Airline Market-Share, Journal of Advertising Research, 12(5), 31-36.

Paleari, S., Malighetti, P., \& Redondi, R. (2010). A comparative study of airport connectivity in China, Europe and US: Which network provides the best service to passengers? Transportation Research Part E: Logistics and Transportation Review, 46(2), 198-210.

Piga, C. A. \& Bachis, E. (2007). Hub Premium, Airport Dominance and Market Power in the European Airline Industry. Working Paper

Shepherd, W. G. (1984). "Contestability" vs. Competition. The American Economic Review, 74(4), 572-587.

Tretheway, M.W., \& Kincaid, I.S. (2005). The Effect of Market Structure on Airline Prices: A Review of Empirical Results. Journal of Air Law and Commerce, 70(3), 466-498.

U.S. General Accounting Office. (1990). Airline Competition: Higher Fares and Reduced Competition at Concentrated Airports. Report.

Vowles, T. M. (2006). Airfare pricing determinants in hub-to-hub markets. Journal of Transport Geography, 14(1), 15-22.

Wooldridge, J. M. (2010). Econometric analysis of cross section and panel data, Cambridge, Massachusetts: MIT Press, 2010; $2^{\text {nd }}$ ed.

Yang, X., Keat Tok, S., \& Su, F. (2008). The privatization and commercialization of China's airports. Journal of Air Transport Management, 14(5), 243-251.

Zhang, A., \& Chen, H. (2003). Evolution of China's air transport development and policy towards international liberalization. Transportation Journal, Spring, 32-49.

Zhang, Y., \& Round, D. K. (2009). Policy Implications of the Effects of Concentration and Multimarket Contact in China's Airline Market. Review of Industrial Organization, 34(4), 307-326. 



\section{APPENDICES}

\section{Appendix A. Definition of Freedoms of the Air}

The freedoms of the air are a set of commercial aviation rights granting a country's airlines the privilege to enter and/or land in another country's airspace. An airline can provide aviation services in the international markets only if it can get the necessary air freedoms, which are included in the bilateral Air Service Agreements (ASAs) between its home country and the other foreign countries involved. There are nine air freedoms defined as follows:

First Freedom of the Air - the right or privilege, in respect of scheduled international air services, granted by one State to another State or States to fly across its territory without landing.

Second Freedom of the Air - the right or privilege, in respect of scheduled international air services, granted by one State to another State or States to land in its territory for non-traffic purposes.

Third Freedom of The Air - the right or privilege, in respect of scheduled international air services, granted by one State to another State to put down, in the territory of the first State, traffic coming from the home State of the carrier.

Fourth Freedom of The Air - the right or privilege, in respect of scheduled international air services, granted by one State to another State to take on, in the territory of the first State, traffic destined for the home State of the carrier.

Fifth Freedom of The Air - the right or privilege, in respect of scheduled international air services, granted by one State to another State to put down and 
to take on, in the territory of the first State, traffic coming from or destined to a third State.

Sixth Freedom of The Air - the right or privilege, in respect of scheduled international air services, of transporting, via the home State of the carrier, traffic moving between two other States.

Seventh Freedom of The Air - the right or privilege, in respect of scheduled international air services, granted by one State to another State, of transporting traffic between the territory of the granting State and any third State with no requirement to include on such operation any point in the territory of the recipient State, i.e. the service need not connect to or be an extension of any service to/from the home State of the carrier.

Eighth Freedom of The Air - the right or privilege, in respect of scheduled international air services, of transporting cabotage traffic between two points in the territory of the granting State on a service which originates or terminates in the home country of the foreign carrier or (in connection with the Seventh Freedom of the Air) outside the territory of the granting State.

Ninth Freedom of The Air - the right or privilege of transporting cabotage traffic of the granting State on a service performed entirely within the territory of the granting State.

Source: http://www.icao.int/Pages/freedomsAir.aspx based on the Manual on the Regulation of International Air Transport (Doc 9626, Part 4). 


\section{Appendix B . Correlation Matrices for the Models}

Table B-1 Correlation Matrix for Economy Class Models

\begin{tabular}{|c|c|c|c|c|c|c|c|c|c|}
\hline & & 1 & 2 & 3 & 4 & 5 & 6 & 7 & 8 \\
\hline 1 & DepShare & & & & & & & & \\
\hline 2 & InDepHHI & 0.131 & & & & & & & \\
\hline 3 & ArrShare & 0.0399 & 0.133 & & & & & & \\
\hline 4 & InArrHHI & 0.0795 & 0.104 & 0.6323 & & & & & \\
\hline 5 & d_RouteShare* & 0.3938 & 0 & 0.3147 & 0 & & & & \\
\hline 6 & InRouteHHI & 0.1723 & 0.1242 & 0.4872 & 0.5825 & 0 & & & \\
\hline 7 & InFreq & 0.1952 & 0.0787 & -0.0067 & -0.3017 & 0.5425 & -0.4073 & & \\
\hline 8 & InPop & -0.0558 & -0.1529 & -0.1424 & -0.2134 & 0 & -0.2406 & 0.1652 & \\
\hline 9 & Inincome & -0.037 & 0.0399 & -0.2383 & -0.3934 & 0.0001 & -0.3027 & 0.2962 & -0.0068 \\
\hline
\end{tabular}

*Notes: d_RouteShare represents the mean-centring transformation for RouteShare.

Table B-2 Correlation Matrix for Premium Class Models

\begin{tabular}{|c|c|c|c|c|c|c|c|c|c|}
\hline & & 1 & 2 & 3 & 4 & 5 & 6 & 7 & 8 \\
\hline 1 & DepShare & & & & & & & & \\
\hline 2 & InDepHHI & 0.1111 & & & & & & & \\
\hline 3 & ArrShare & -0.0249 & 0.115 & & & & & & \\
\hline 4 & InArrHHI & 0.0622 & 0.1009 & 0.5423 & & & & & \\
\hline 5 & d_RouteShare & 0.3731 & 0.0122 & 0.3163 & -0.0446 & & & & \\
\hline 6 & InRouteHHI & 0.1964 & 0.1202 & 0.4372 & 0.4978 & -0.0154 & & & \\
\hline 7 & InFreq & 0.1478 & 0.1122 & 0.0786 & -0.2269 & 0.5627 & -0.3427 & & \\
\hline 8 & InPop & -0.0583 & -0.164 & -0.1573 & -0.2268 & -0.0057 & -0.231 & 0.1421 & \\
\hline 9 & Inincome & -0.0493 & 0.041 & -0.1567 & -0.3331 & -0.0028 & -0.2356 & 0.2377 & -0.0573 \\
\hline
\end{tabular}

*Notes: d_RouteShare represents the mean-centring transformation for RouteShare. 